\title{
K-FIX(GT): A Computer Program for \\ Modeling the Expansion Phase \\ of Steam Explosions within \\ Complex Three Dimensional Cavities \\ (U)
}

\author{
M. L. Hyder \\ Safety Technology Section \\ Yousef M. Farawila, Said I. Abdel-Khalik, \\ and Peter J. Halvorson \\ Georgia Institue of Technology
}

May 1992

PREPARED FOR THE U.S. DEPARTMENT OF ENERGY UNDER CONTRACT NO. DE-AC09-89SR18035

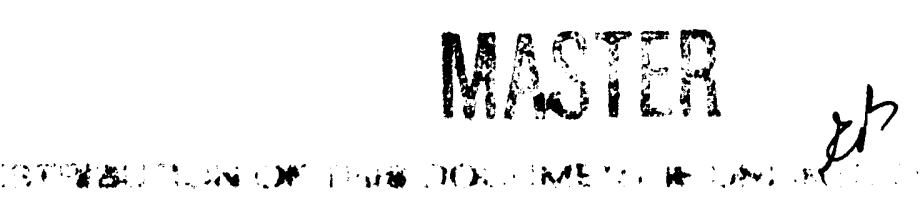


DOCUMENT: WSRC-RP-92-656

TITLE: K-FIX(GT): A Computer Program for Modeling the Expansion Phase of Steam Explosions within Complex Three Dimensional Cavities (U)

APPROVALS

M. L. Heder Author

I. K. Pain Derivative Classifier

D. K. Allison Technical Reviewer

S. B. Whitfield Editor
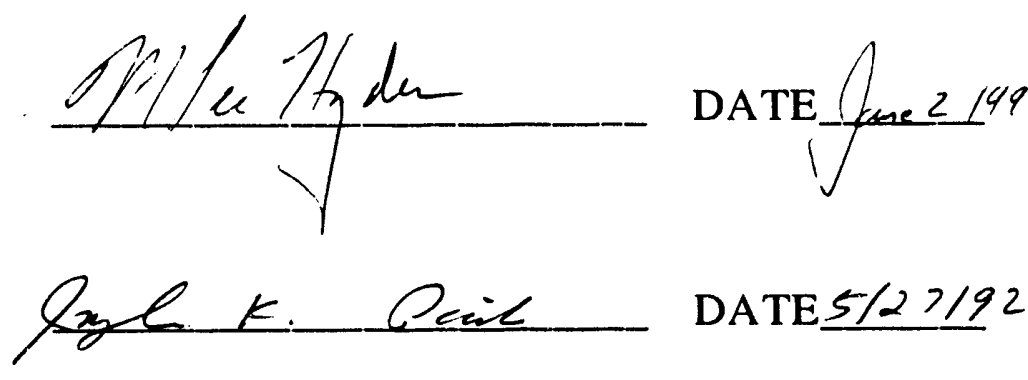

David K allow

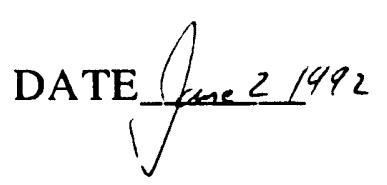

DATE $5 / 27 / 92$

DATE $7-13-92$

Shirley B. Whatgeeldate $2 / 13 / 92$

L. A. Wooten, Manager

Lanate

DATE $/ 0 / 02 / 92$

Safety Analysis and Engineering Service

M. J. Hitchler, Manager

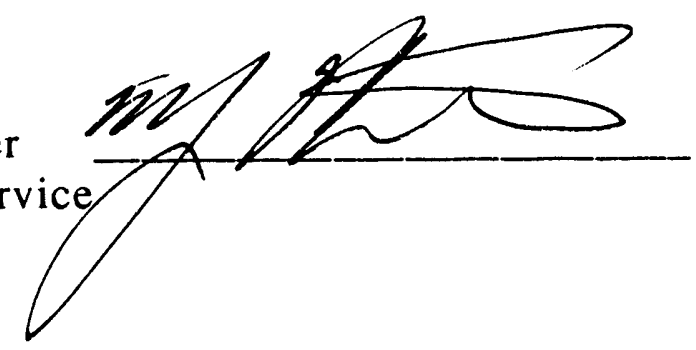
DATE LOFL/Y2 


\section{Introduction}

In the development of the Severe Accident Analysis Program for the Savannah River production reactors, it was recognized that certain accidents have the potential for causing damaging steam explosions. Steam explosions can occur when metals, such as the aluminum-based fuel used at Savannah River, are melted and come into contact with water. This condition is unstable, and local turbulence can lead to the generation of great quantities of steam within a few milliseconds. This phenomenon has been observed in several reactor incidents and experiments (BORAX, SPERT-1, SL-1, probably Chernobyl) where it caused damage to the reactor and associated structures. The massive SRS reactor buildings are likely to withstand any imaginable steam explosion. However, reactor components and building structures including hatches, ventilation ducts, etc., could be at risk if such an explosion occurred.

Except for bounding techniques that returned very conservative values, no tools were available to estimate the effects of such explosions on actual structures. To meet this need, the Savannah River Laboratory (now the Savannah River Technology Center) contracted with the Georgia Institute of Technology Research Institute for development of a computer-based calculational tool for estimating the effects of steam explosions. Prof. S. I. Abdel-Khalik of the Nuclear Engineering Department of Georgia Tech was the principal investigator under this contract. The program to be developed was a modificatic $n$ of the K-FIX fluid dynamics code, modified specifically to simulate the expansion phase of steam explosions. Results from such calculations could then be coupled with structural response codes to predict the response of adjacent structures.

The goal for this study was to develop a computer code that could be used parametrically to predict the effects of various steam explosions on their surroundings. This would be able to predict whether a steam explosion of a given magnitude would be likely to fail a particular structure. This would require, of course, that the magnitude of the explosion be specified through some combination of judgment and calculation.

The requested code, identified as the K-FIX(GT) code, was developed and delivered by the contractor, along with extensive documentation. The several individual reports that constitute the documentation are each being issued as a separate WSRC report. Documentation includes several model calculations, and representation of these in graphic form. This report incorporates Report GTRSR-008, which gives detailed instructions for the use of the code, including identification of all input parameters required. This represents essential information for the code user.

The K-FIX code has been delivered to SRS and turned over to the Probabilistic Risk Assessment group of the Safety Technology Section for their use in evaluating risks from steam explosions. Additionally, the $\mathrm{K}$ FIX(GT) code has also been used by its developers to address a specific 
problem of interest to SRS: the explosion of molten control rod material contacted with water in a septifoil. Results of this study are published in a separate report. No calculations made at SRS have as yet been reported.

Currently only the original form of K-FIX(GT) exists at SRS. Development of the code is continuing at Georgia Tech, but this development is supported by other sources. There are no current plans to obtain updated versions of the code for SRS use. 


\section{Contents}

Abstract iv

1 Introduction 1

2 K-FIX(GT) Input 3

2.1 Introduction . . . . . . . . . . . . . . . 3

2.2 Input File . . . . . . . . . . . . . . . . . . . 3

2.3 Input Variables . . . . . . . . . . . . . . . 5

3 Compilation and Running of K-FIX(GT) 17

4 K-FIX(GT) Output $\quad 19$

4.1 Introduction . . . . . . . . . . . . . . . . . . . . . . . 19

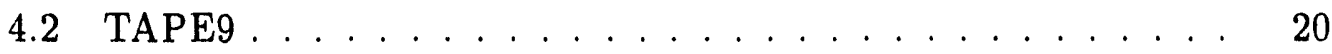

4.3 TAPE15 ....................... 20

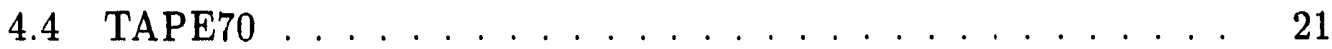

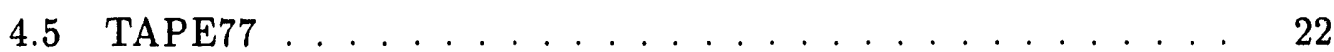

5 Graphics $\quad 23$

5.1 Introduction . . . . . . . . . . . . . . . . . 23

5.2 Time Plots. . . . . . . . . . . . . . . . . . 23

TMPLT Program . . . . . . . . . . . . . . . . . . . 24

TMTHIN Program . . . . . . . . . . . . . . . . . . 25

PLOTGENERAL Program . . . . . . . . . . . . . . . . . 27

TP Program . . . . . . . . . . . . . . . . . . . . . . . . . 28

TPA2B Program . . . . . . . . . . . . . . . . . . 30

5.3 Two Dimensional Plots . . . . . . . . . . . . . . . . 30 
TWOD Program . . . . . . . . . . . . . . . . 31

TWODSLCT Program . . . . . . . . . . . . . . . . . . . . . . 32

5.4 Computer Animations . . . . . . . . . . . . . . . . . . 33

ANIM Program . . . . . . . . . . . . . . . . . . . 33

PREPROC Program .................... 34

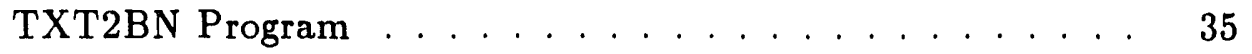

$\begin{array}{ll}\text { Bibliography } & 36\end{array}$

Appendix: K-FIX(GT) Variables 37 


\begin{abstract}
This document is a user's manual for the K-FIX(GT) computer code. The code is a new version of K-FIX(3D), the two-fluid, three-dimensional, transient fluid dynamics code developed at Los Alamos National Laboratory. The Georgia Tech modifications have been made in order to be able to simulate the expansion phase of steam explosions. For a given explosion, the interaction zone is represented by a single high pressure bubble as an initial condition; subsequent calculations are made to determine the hydrodynamic responses of the system, including the pressure histories at the test vessel or confinement walls. The main modifications involved in developing the K-FIX(GT) code consist of adding new components representing a non-condensible gas, air, and debris particles to the two-phase water mixture, and including new exchange functions for mass, momentum, and energy which are particularly suited to this type of fast transient. In addition, state equations for water, debris, and air are incorporated into the code. Explosion energetics, i.e. the work and mechanical energy yield, are calculated as a measure of the destructive potential of the explosion. None of the features of the original K-FIX(3D) code have been lost.

This manual provides user instructions for the use of K-FIX(GT), along with descriptions and user instructions for a set of auxiliary programs developed for data handling, plotting one and two dimensional data sets, and computer animations for flow visualization.
\end{abstract}




\section{Chapter 1}

\section{Introduction}

This work has been undertaken in response to the need for analyzing the consequences of hypothetical severe accidents involving core meltdown and energetic steam explosions in the reactor building of the Savannah River Plant. A possible accident scenario begins with loss of coolant or loss of pumping with subsequent core meltdown. The bottom of the reactor tank fails and a substantial amount of hot core material melts through and falls into the underlying pin room. An energetic explosion may occur due to the thermal interaction between the falling melt and water in the pool covering the floor of the reactor building.

Many uncertainties exist in the analysis of this type of problem. Amongst the uncertainties are the amount of the released molten core material, and the fraction of the released molten material which undergos ine fragmentation and, thus, participates in the explosive interaction. Experimental results have shown that the fraction of melt participation, mechanical energy yield, and pressure vary widely even for repeat tests with very similar initial setup. Currently, no deterministic model exists which can adequately predict such quantities in an apriori fashion, inasmuch as they are physically sensitive to slight changes in the initial conditions.

The scope of the problem under study is focussed towards determining the consequences of steam explosions of specified magnitudes; none of the above uncertainties are directly included in the analysis. Instead, the initial conditions of the explosion source term are parametrically specified as a steam bubble of high temperature and pressure. The thermodynamic state of the bubble as well as its volume represent an explosion of a given strength prior 
to the expansion stage of its development. The problem is thus reduced to the analysis of the expansion phase of a steam explosion and the subsequent transient in a realistic three-dimensional representation of a reactor building.

Two broad tasks are involved. The first task deals with development of the tools required for the analysis. To that end, the Los Alamos two-fluid, threedimensional transient code K-FIX $[1,2]$ has been modified to produce the $\mathrm{K}-\mathrm{FIX}(\mathrm{GT})$ code. The modifications entail adding a noncordensible gas and debris material components to the original two-phase one-con:ponent model. Also, mass, momentum, and energy exchange models which are particularly suitable for producing stable solutions for the fast transient problems at hand, are developed and incorporated into the new code. The models used in the $\mathrm{K}-\mathrm{FIX}(\mathrm{GT})$ code as well as a test case simulating a steam explosion experiment, for the purpose of validating the code, are presented in a companion report [3]. The results of the simulated experiment demonstrate the capability of the K-FIX(GT) models to perform the second task of this study, namely, the analysis of the transients resulting from hypothetical steam explosions in the Savannah River Plant (SRP) confinement building. These results have been presented in reference [4].

This report is a User's Manual for the K-FIX(GT) code. The remainder of the report is organized as follows. A description of the K-FIX(GT) input and an explanation of the various input variables and their default values are given in Chapter 2. Chapter 3 describes how the code can be compiled and run on different computers including CDC mainframes, Cray supercomputers, Iris workstations, and Sun workstations. The K-FIX(GT) output files are described in Chapter 4. Various graphics outputs are described in Chapter 5. A list of all of the main K-FIX(GT) variables, their algebraic symbols, and definitions is given in Appendix A.

This manual is based on the two previous K-FIX manuals $[1,2]$. Descriptions for many of the variables are taken directly from those manuals in order to produce a stand alone manual for K-FIX $(\mathrm{GT})$. 


\section{Chapter 2}

\section{K-FIX(GT) Input}

\subsection{Introduction}

K-FIX(GT) gets all of its input from the standard input, which may be redirected to an input file on most computers. Before reading any variables, the program sets up default values for all the input variables. The program tries to read a character string as a title for the run, then reads the contents of the KFIX3D namelist. The following section lists an example input file; a description of all the input variables follows.

\section{$2.2 \quad$ Input File}

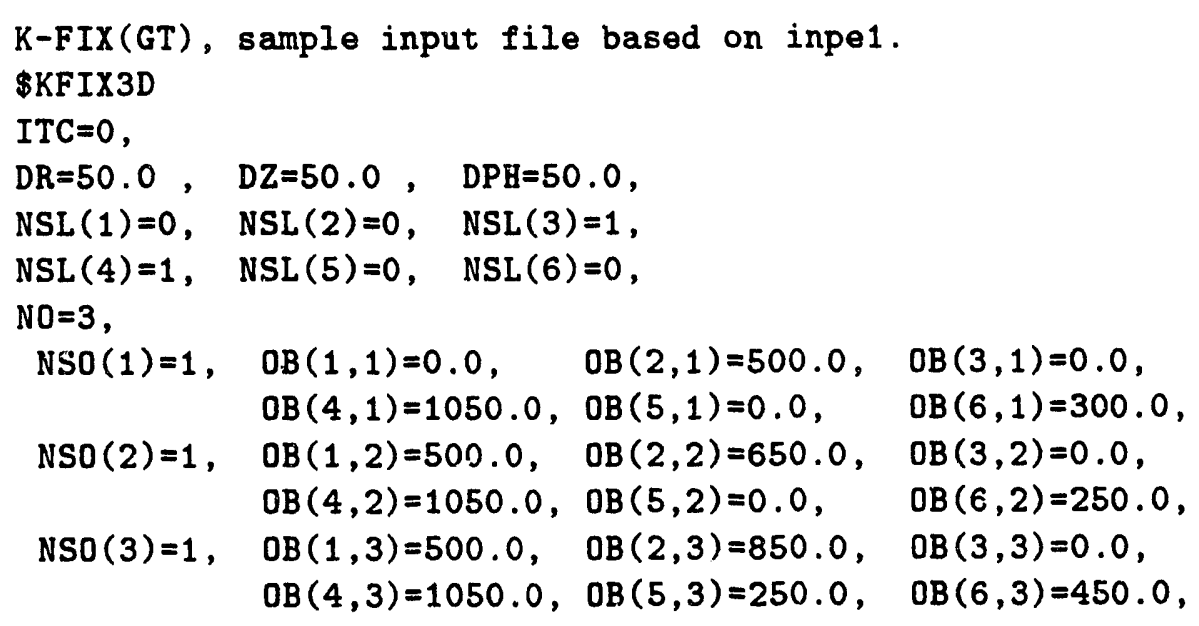




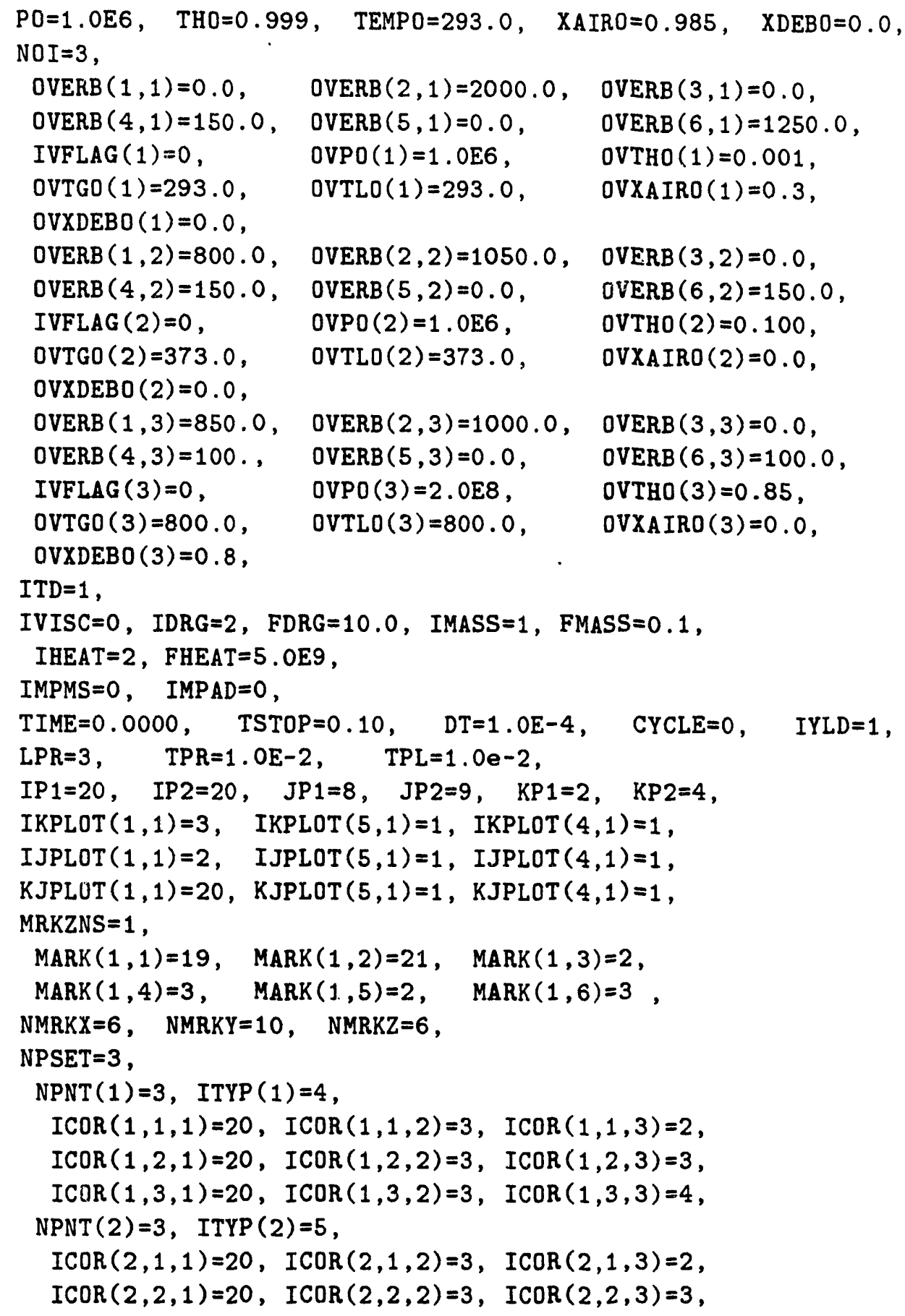




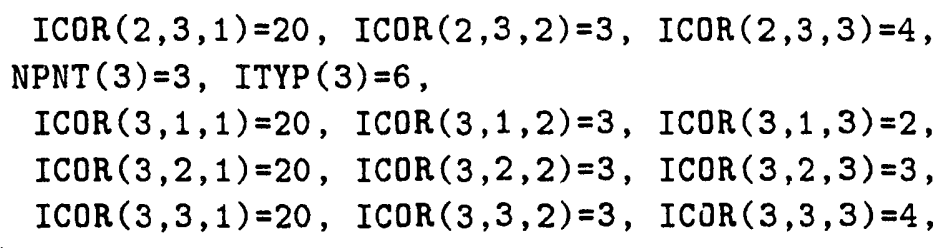

\subsection{Input Variables}

CDEB Heat capacity of the debris in ergs / ( cc $\mathrm{K})$. Default = $1.47425 \mathrm{e}+7$ ( Aluminum).

CYCLE The integer number of the computational cycle at which the computation is to begin. CYCLE is incremented by one each time step. Negative CYCLE values cause prints and plots to be produced every cycle until CYCLE $>1$, then TPR, TPL, and TPLD take over. Defaults to 0 .

DEBRAD Average debris particle radius. Defaults to 0.5.

DPH $\delta \phi($ or $\delta Z$ ), the cell dimensior in the azimuthal ( or Z) direction. Defaults to $100 \mathrm{~cm}$.

DR $\delta r$ ( or $\delta X$ ), the cell dimension in the radial (or $\mathrm{X}$ ) direction. Defaults to $100 \mathrm{~cm}$.

DT $\delta t$, the computational time step. Defaults to $1.0 \mathrm{e}-3 \mathrm{sec}$.

$\mathrm{DZ} \delta z$ ( or $\delta Y$ ), the cell dimension in the axial (or $\mathrm{Y}$ ) direction. Defaults to $100 \mathrm{~cm}$.

FDRG Used to calculated KDRAG in subroutine KDRAGS. Defaults to $1.0 \mathrm{e}+6 \mathrm{~g} /(\mathrm{cc} \mathrm{sec})$.

FHEAT Used to calculate RHEAT in subroutine RHEATS. 
$\mathrm{FLO}(\mathrm{M}) \quad \mathrm{M}=1,16$.

Axial coordinates of the flow openings along the bottom, left, top, and right computing mesh boundaries, respectively. Coordinates of openings along the right and left boundaries must be integral multiples of $\delta z\left(\delta Y^{r}\right)$; those along the top and bottom boundaries must be integral multiples of $\delta r(\delta X)$. The openings on the bottom and left boundaries are by definition inflow openings; those along the top and right boundaries are outflow openings. A maximum of two openings may be specified along each boundary. FLO(1) - FLO(4) define the r coordinates of the bottom openings. FLO(1) is the low radius of the first opening, $F L O(2)$ is the high radius of the first opening. FLO(3) and $F L O(4)$ are the low and high radii of the second opening. For no openings, set all four to 0.0 , for one opening set $F L O(3)$ and $\mathrm{FLO}(4)$ equal to $\mathrm{FLO}(2)$.

Similarly FLO(5) - FLO(8) define the z-coordinates of the left boundary opening, FLO(9) - FLO(12) define the r-coordinates of the top boundary openings, and FLO(13) - FLO(16) define the z-coordinates of the right boundary openings. FLO() defaults to 0.0 .

FLOA(M) $\quad \mathrm{M}=1,16$.

Azimuthal coordinates of the flow openings along the bottom, left, top, and right computing mesh boundaries, respectively. Coordinates of the openings must be integral multiples of $\delta \phi$ $(\delta Z)$. The azimuthal extension of each opening is defined by two coordinates, the first of which is the smaller. For example, the first opening on the bottom boundary of the computing mesh is described by its inner and outer radial coordinates, $\mathrm{FLO}(1)$ and $F L O(2)$, and its smaller and larger azimuthal coordinates, FLOA(1) and FLOA(2). Note that flow openings are not permitted in azimuthal planes.

FMASS Multiplicative factor $(\leq 1)$ used to reduce the mass exchange rate. It acts as a relaxation factor, integrated mass exchange is not significantly affected. Recommended value to use is 0.1 . Used in subroutine MASSX.

GRAV Gravitational acceleration in the axial +z-direction. Defaults to $980.62 \mathrm{~cm} / \mathrm{sec}^{2}$. 
IB2

The number of cells in the radial direction, including those in the two fictitious columns at the right and left boundaries. Defaults to $\mathrm{NX} 1, \mathrm{NX} 1$ should be modified to do a different sized problem.

$\operatorname{ICOR}(\mathrm{L}, \mathrm{M}, \mathrm{N}) \quad \mathrm{L}=1,40 \mathrm{M}=1,6 \mathrm{~N}=1,3$.

The locations for the points to be plotted in the $1 \mathrm{D}$ plots. The data is for the $L^{\text {th }}$ plot, the $M^{\text {th }}$ curve on that plot, and the three coordinates of the point to be plotted $(N=1,3)$. Defaults to 0 .

IDRG

IDRG $=0$, no adjustments

$\mathrm{IDRG}=1, \mathrm{KDRAG}=\mathrm{FDRG}$

IDRG $=2, \mathrm{KDRAG}=\max (\mathrm{FDRG}$, modelled value $)$

$\mathrm{IDRG}=3, \mathrm{KDRAG}=\mathrm{FDRG}{ }^{*}$ model value

$\mathrm{IDRG}=4, \mathrm{KDRAG}=\mathrm{FDRG}$ at edge of lagrangian marker zone, $=$ model otherwise.

IDRG $=5, \mathrm{KDRAG}=\max (\mathrm{FDRG}$, model $)$ at edge of marker zone, $=$ model otherwise.

IDRG $=6, \mathrm{KDRAG}=$ FDRG ${ }^{*}$ model at edge of marker zone, = model otherwise.

IDRG $=7, \mathrm{KDRAG}=\mathrm{FDRG}$ in marker zone, = model otherwise.

$\mathrm{IDRG}=8, \mathrm{KDRAG}=\max (\mathrm{FDRG}$, model $)$ in marker zone, = model otherwise.

IDRG $=9, \mathrm{KDRAG}=\mathrm{FDRG}{ }^{*}$ model in marker zone, $=$ model otherwise.

Defaults to 1 .

IHEAT IHEAT $=0$, basic model to calculate RHEAT

IHEAT $=1$, RHEAT $=$ FHEAT

IHEAT $=2$, RHEAT $=\max ($ FHEAT, model $)$

IHEAT $=3$, RHEAT $=$ FHEAT ${ }^{*}$ model

Defaults to 1 . 
$\operatorname{IJPLOT}(\mathrm{M}, \mathrm{N}) \quad \mathrm{M}=1,10 \mathrm{~N}=1,5$.

IJPLOT $(M, N)$ is the plot control array for plots in the $(r, z)$ plane with a constant azimuthal coordinate specified by the value of $\operatorname{IJPLOT}(1, \mathrm{~N})$. The $\mathrm{N}$ index allows a complete set of plots at up to five different azimuthal coordinates. If $\mathrm{IJ}$ $\operatorname{PLOT}(1, N)=0$, then no plots are produced for that value of N. IJPLOT $(M \neq 1, N)=1$ indicates that a plot of the $M^{\text {th }}$ and $\mathrm{N}$ is desired, a 0 indicates that no plot for that $\mathrm{M}$ and $\mathrm{N}$ is desired. IJPLOT $(M, N)$ defaults to 0 for all $M$ and N. Plots of gas velocity, liquid velocity, and lagrangian marker position are produced automatically. Plots can be obtained for the following quantities if $\operatorname{IJPLOT}(\mathbf{M} \neq 1, \mathrm{~N})=1$.

$\operatorname{IJPLOT}(4, \mathrm{~N})=$ Void fraction contour plot.

$\operatorname{IJPLOT}(5, N)=$ Pressure contour plot.

$\operatorname{IJPLOT}(6, \mathrm{~N})=$ Gas temperature contour plot.

$\operatorname{IJPLOT}(\bar{\tau}, \mathrm{N})=$ Liquid temperature contour plot.

$\operatorname{IJPLOT}(8, \mathrm{~N})=$ Mass exchange rate contour plot.

$\operatorname{IJPLOT}(9, N)=$ Air density (macroscopic) contour plot.

$\operatorname{IJPLOT}(10, \mathrm{M})=$ Debris density $($ macroscopic $)$ contour plot.

$\operatorname{IKPLOT}(\mathrm{M}, \mathrm{N}) \mathrm{M}=1,12$.

IKPLOT(M,N) is the plot control array for plots in the $(r, \phi)$ plane with a constant axial coordinate specified by the value of $\operatorname{IKPLOT}(1, \mathrm{~N})$. The meaning of the indices is the same as those of IJPLOT. IKPLOT $(M, N)$ defaults to 0 for all $M$ and $N$.

IMASS IMASS $=0$, no mass transfer

IMASS $=1$, use Farawila's model

IMASS $=2$, use Theofanous' model

IMASS $=3$, use modified Theofanous' model

Defaults to 0 .

IMPAD Controls whether the air and debris continuity equations are solved inside or outside the iteration loop. IMPAD $=0$, solve outside ( recommended), IMPAD $=1$, solve inside the loop. Defaults to 0 .

IMPMS Controls whether the mass exchange equations are solved inside or outside the iteration loop. IMPMS $=0$, solve outside, IMPMS $=1$, solve inside the loop. Defaults to 0 . 
IP 1

IP2

IRESET

ITC

ITD

$\operatorname{ITYP}(\mathrm{M}) \quad \mathrm{M}=1,40$.

The type of data to be plotted on the $M^{\text {th }} 1 \mathrm{D}$ plot. The types are the same as for $2 \mathrm{D}$ plots. Six quantities used for energetics are automatically added to each data set. These variables are EXPKE, SURKE, EXPWA, SURWA, EXPWD, and SURWD. ITYP defaults to 0 .

IVFLAG(M) $\mathrm{M}=1,16$.

IVISC Determines whether to include viscous terms in the momentum equation. IVISC $=0$, do not include, IVISC $=1$, include viscous terms. Defaults to 0 .

IYLD Determines whether to calculate marker motions and energetics. IYLD $=0$, do not include, IYLD $=1$, do include markers and energetics. Defaults to 0 .

JB2

JP1

JP2
The number of cells in the axial direction, including those in the two fictitious columns at the bottom and top boundaries. Defaults to NX2, NX2 should be modified to do a different sized problem.

Starting value of $\mathrm{J}$ for printing data to tape9. Defaults to 1 . Final value of $\mathrm{J}$ for printing data to tape9. Defaults to NX2. 
KB2

$\mathrm{KP} 1$

KP2

The number of cells in the azimuthal direction, including those in the two fictitious columns at the fore and aft boundaries. Defaults to NX3, NX3 should be modified to do a different sized problem.

$\mathrm{KJPLOT}(\mathrm{M}, \mathrm{N}) \mathrm{M}=1,12 \mathrm{~N}=1,5$.

Starting value of $\mathrm{K}$ for printing data to tape9. Defaults to 1 .

Final value of $\mathrm{K}$ for printing data to tape9. Defaults to NX2.

$\mathrm{KJPLOT}(\mathrm{M}, \mathrm{N})$ is the plot control array for plots in the $(z, \phi)$ plane with a constant radial coordinate specified by the value of $\operatorname{KJPLOT}(1, N)$. The meaning of the indices is the same as those of IJPLOT. KJPLOT(M,N) defaults to 0 for all $M$ and $N$.

LPR

$\mathrm{LPR}=0$, no writes to tape9, tape70, or tape 77 .

$\mathrm{LPR}=1$, no writes to tape9, do writes to tape70 and tape77.

$\mathrm{LPR}=2$, no writes to tape70 or tape 77 , do writes to tape9.

$\mathrm{LPR}=3$, do writes to tape9, tape70, and tape77.

Defaults to 3 .

$\operatorname{MARK}(\mathrm{M}, \mathrm{N}) \quad \mathrm{M}=1,10 \mathrm{~N}=1,6$.

Specifies the limits for each marker region. A new $M$ is used for each region, $\mathrm{N}=1$ through 6 hold the coordinates xlow, xhigh, ylow, yhigh, zlow, zhigh respectively. MARK defaults to 0 .

MRKZNS Specifies the number of marker zones to be read, defaults to 0 .

NFILE

NOT IN USE. Replaced by automatic writes to tape15. The number of the last data set on tape 5 ( only used when tape 5 is written). Defaults to 1 .

NMRKX The number of markers along the X-direction in each cell. The total number of markers per cell is NMRKX * NMRKY * NMRKZ. NMRKX defaults to 4.

NMRKY The number of markers along the Y-direction in each cell. NMRKY defaults to 4 .

NMRKZ The number of markers along the Z-direction in each cell. NMRKZ defaults to 4 .

NO The number of interior obstacles. Each obstacle must contain at least two cells in each direction to accommodate the velocity boundary conditions. By overlaying several obstacles, complex shapes can be obtained. There are 0 obstacles by default. 
NOI The number of overlay regions. There are initial conditions that apply to the entire computational mesh, then specific regions can be overlayed with new initial conditions. NOI defaults to 0 . $\operatorname{NPNT}(\mathrm{M}) \quad \mathrm{M}=1,40$.

The number of lines to put on a $1 \mathrm{D}$ plot ( the plot number is determined by M). Defaults to 0 .

NPSET

NSDMP

$\mathrm{NSL}(\mathrm{M})$

The number of $1 D$ plots to be produced. Defaults to 0 .

NOT IN USE. Replaced by automatic writes to tape15. The number of cycles ( time steps) between writing data sets to tape 5 (only used when tape5 is written). Defaults to 10 .

$\mathrm{M}=1,6$.

Indicates free-slip or no-slip boundary conditions for rigid walls around the computing mesh perimeter. $0=$ free-slip, $1=$ noslip. Values are assigned for the bottom, left, top, right, fore, and aft boundaries, in that order. The assigned values are ignored across inflow or outflow openings. The default values are no-slip.

$\mathrm{NSO}(\mathrm{M}) \quad \mathrm{M}=1, \mathrm{NO}$.

Indicates free-slip ( 0 ) or no-slip ( 1 ) boundary conditions for each obstacle. Defaults to no-slip.

NTD

The number of the data set on tape 5 to be used for initial conditions ( only used when tape 5 is read). Defaults to 1.

NWDMP NOT IN USE. Replaced by automatic writes to tape15. The number of the first dump to be written on iape5 (only used when tape 5 is written). Generally NWDMP $=$ NFILE +1 . Defaults to 2 .

$\mathrm{OB}(\mathrm{M}, \mathrm{N}) \quad \mathrm{M}=1,6 \mathrm{~N}=1, \mathrm{NO}$.

$\mathrm{OB}(1, \mathrm{~N})=$ radial coordinate of the left side of the obstacle.

$\mathrm{OB}(2, N)=$ radial coordinate of the right side of the obstacle.

$\mathrm{OB}(3, N)=$ axial coordinate of the bottom side of the obstacle.

$\mathrm{OB}(4, \mathrm{~N})=$ axial coordinate of the top side of the obstacle.

$\mathrm{OB}(5, \mathrm{~N})=$ azimuthal coordinate of the fore side of the obstacle.

$\mathrm{OB}(6, N)=$ azimuthal coordinate of the aft side of the obstacle.

Default values are 0.0 . 
$\operatorname{OVERB}(\mathrm{M}, \mathrm{N}) \quad \mathrm{M}=1,6 \mathrm{~N}=1, \mathrm{NOI}$.

Coordinates of each overlay region. $\mathrm{M}=1,6$ corresponds to Xlow, Xhigh, Ylow, Yhigh, Zlow, and Zhigh. Defaults are 0.0.

$\operatorname{OVPO}(\mathrm{M}) \quad \mathrm{M}=1, \mathrm{NOI}$.

Pressure of the $M^{\text {th }}$ overlay region. Defaults to 0.0 .

OVTGO(M) M=1,NOI.

Gas temperature of the $M^{\text {th }}$ overlay region. Defaults to 0.0 .

$\operatorname{OVTHO}(\mathrm{M}) \quad \mathrm{M}=1, \mathrm{NOI}$.

Void fraction of the $M^{\text {th }}$ overlay region. Defaults to 0.0 .

$\operatorname{OVTLO}(\mathrm{M}) \quad \mathrm{M}=1, \mathrm{NOI}$.

Liquid temperature of the $M^{\text {th }}$ overlay region. Defaults to 0.0 .

OVUOG(M) M=1,NOI.

Gas velocity in the radial direction for the $M^{\text {th }}$ overlay region. Defaults to 0.0 .

OVUOL(M) $\quad \mathrm{M}=1, \mathrm{NOI}$.

Liquid velocity in the radial direction for the $M^{\text {th }}$ overlay region. Defaults to 0.0 .

OVVOG(M) M=1,NOI.

Gas velocity in the axial direction for the $M^{\text {th }}$ overlay region. Defaults to 0.0 .

$\operatorname{OVVOL}(\mathrm{M}) \quad \mathrm{M}=1, \mathrm{NOI}$.

Liquid velocity in the axial direction for the $M^{\text {th }}$ overlay region. Defaults to 0.0 .

OVWOG(M) M=1,NOI.

Gas velocity in the azimuthal direction for the $M^{\text {th }}$ overlay region. Defaults to 0.0 .

OVWOL(M) $\mathrm{M}=1$, NOI.

Liquid velocity in the azimuthal direction for the $M^{\text {th }}$ overlay region. Defaults to 0.0 . 
OVXAIRO(M) $\mathrm{M}=1, \mathrm{NOI}$.

Air mass fraction of the $M^{\text {th }}$ overlay region. Defaults to 0.0 .

OVXDEBO(M) M=1,NOI.

Air mass fraction of the $M^{\text {th }}$ overlay region. Defaults to 0.0 .

PINB The pressure of the fluid entering the bottom inflow opening along the left computing mesh boundary. Defaults to 0.0 .

PINL The pressure of the fluid entering tiae left inflow opening along the bottom computing mesh boundary. Defaults to 0.0 .

PINR The pressure of the fluid entering the right inflow opening along the bottom computing mesh boundary. Defaults to 0.0 .

PINT The pressure of the fluid entering the top inflow opening along the left computing mesh boundary. Defaults to 0.0 .

PO The initial pressure.

RODEB The density of the debris particles, $\rho_{\text {deb }}$. Defaults to $2.7 \mathrm{~g} / \mathrm{cc}$.

$\operatorname{SCALE}(\mathrm{M}) \quad \mathrm{M}=1,4$.

$\operatorname{SCALE}(1)=$ length scale.

$\operatorname{SCALE}(2)=$ velocity scale.

$\operatorname{SCALE}(3)=$ density scale.

$\operatorname{SCALE}(4)=$ temperature scale.

NOT IN USE. All inputs should now be in cgs units. Scale factors are not used. These are scale factors used to establish the dimensionless input data. The scale factors default to 1.0 .

TEMPINB The temperature of the fluid entering the bottom inflow opening along the left computing mesh boundary. Defaults to 0.0 .

TEMPINL The temperature of the fluid entering the left inflow opening along the bottom computing mesh boundary. Defaults to 0.0.

TEMPINR The temperature of the fluid entering the right inflow opening along the bottom computing mesh boundary. Defaults to 0.0 .

TEMPINT The temperature of the fluid entering the top inflow opening along the left computing mesh boundary. Defaults to 0.0 .

TEMPO The initial temperature of the liquid and gas. Defaults to 293 $\mathrm{K}$.

THINB The void fraction of the fluid entering the bottom inflow opening along the left computing mesh boundary. Defaults to 0.0 . 
THINL The void fraction of the fluid entering the left inflow opening along the bottom computing mesh boundary. Defaults to 0.0 .

THINR The void fraction of the fluid entering the right inflow opening along the bottom computing mesh boundary. Defaults to 0.0 .

THINT The void fraction of the fluid entering the top inflow opening along the left computing mesh boundary. Defaults to 0.0 .

THO

TIME The initial void fraction. Defaults to 0.5.

The initial time for the problem. TIME is incremented by DT in each cycle. Default TIME is 0.0 sec.

TPL

TPLD

The time interval between writes to tape77. Defaults to $1.0 \mathrm{e}-2$ sec.

TPR

TSTOP

NOT IN USE.

The time interval between writes to tape9. Defaults to $1.0 \mathrm{e}-2$ sec.

ber of computational cycles to be made is (TSTOP-TIME)/DT. Default TSTOP is $0.1 \mathrm{sec}$.

UINB The radial velocity of the liquid and gas entering the bottom inflow opening along the left computing mesh boundary. Defaults to 0.0 .

UINL The radial velocity of the liquid and gas entering the left inflow opening along the bottom computing mesh boundary. Defaults to 0.0 .

UINR The radial velocity of the liquid and gas entering the right inflow opening along the bottom computing mesh boundary. Defaults to 0.0 .

UINT The radial velocity of the liquid and gas entering the top inflow opening along the left computing mesh boundary. Defaults to 0.0 .

UO The initial radial velocity of the liquid and gas. Defaults to 1.e-30.

VINB The axial velocity of the liquid and gas entering the bottom inflow opening along the left computing mesh boundary. Defaults to 0.0 .

VINL The axial velocity of the liquid and gas entering the left inflow opening along the bottom computing mesh boundary. Defaults to 0.0 . 
VINR

VINT

vo

WINB

WINL

WINR

WINT

WO

XAIRINB

XAIRINL

XAIRINR

XAIRINT

XAIRO

XDEBINB
The axial velocity of the liquid and gas entering the right inflow opening along the bottom computing mesh boundary. Defaults to 0.0 .

The axial velocity of the liquid and gas entering the top inflow opening along the left computing mesh boundary. Defaults to 0.0 .

The initial axial velocity of the liquid and gas. Defaults to 1.e30.

The azimuthal velocity of the liquid and gas entering the bottom inflow opening along the left computing mesh boundary. Defaults to $\mathbf{0 . 0}$.

The azimuthal velocity of the liquid and gas entering the left inflow opening along the bottom computing mesh boundary. Defaults to 0.0 .

The azimuthal velocity of the liquid and gas entering the right inflow opening along the bottom computing mesh boundary. Defaults to 0.0 .

The azimuthal velocity of the liquid and gas entering the top inflow opening along the left computing mesh boundary. Defaults to 0.0 .

The initial azimuthal velocity of the liquid and gas. Defaults to 1.e-30.

The air mass fraction of the fluid entering the bottom inflow opening along the left computing mesh boundary. Defaults to 0.0 .

The air mass fraction of the fluid entering the left inflow opening along the bottom computing mesh boundary. Defaults to 0.0.

The air mass fraction of the fluid entering the right inflow opening along the bottom computing mesh boundary. Defaults to 0.0 .

The air mass fraction of the fluid entering the top inflow opening along the left computing mesh boundary. Defaults to 0.0 .

The initial mass fraction of air in the gas, $m_{\text {air }} /\left(m_{\text {air }}+m_{\text {vapor }}\right)$. Defaults to 0.0 .

The debris mass fraction of the fluid entering the bottom inflow opening along the left computing mesh boundary. Defaults to 0.0 . 
XDEBINL The debris mass fraction of the fluid entering the left inflow opening along the bottom computing mesh boundary. Defaults to 0.0 .

XDEBINR The debris mass fraction of the fluid entering the right inflow opening along the bottom computing mesh boundary. Defaults to 0.0 .

XDEBINT The debris mass fraction of the fluid entering the top inflow opening along the left computing mesh boundary. Defaults to 0.0 .

XDEBO The initial mass fraction of debris in the liquid, $m_{\text {deb }} /\left(m_{\text {deb }}+\right.$ $\left.m_{\text {water }}\right)$. Defaults to 0.0 . 


\section{Chapter 3}

\section{Compilation and Running of K-FIX(GT)}

$\mathrm{K}$-FIX(GT) has been compiled and run on many different types of computers; including CDC mainframes, Cray supercomputers, Iris workstations, and Sun workstations. The code is almost all fortran 77 , with the exceptions of a NAMELIST used for input, and a function used to get time (in CPU seconds) used by the program ( called SECOND() on the CDC mainframes). The Cyber also has a non-standard way of attaching files to input and output unit numbers, These are part of the program statement, and are commented out on other machines.

The code was found to be insensitive to the number of bits used for the real variables. The Cray and CDC computers used 64 bit variables, and the workstations used 32 bit variables ( although you can use 64 bit variables on the workstation). Test cases produced output that matches out to six digits after thousands of time steps. The cases run at Georgia Tech required from 1 to 8 megabytes of memory ( this is for 32 bit variables; 64 bit variables would require twice as much memory).

The code is not vectorized for best performance on the Cray. Considering delays while waiting in a queue, and timesharing among dozens of users of the NCSA Crays, the Cray was no more than a factor of two faster than a dedicated SPARCstation1 from Sun Microsystems.

The two non-fortran 77 features can cause problems when porting the program to a new computer. The NAMELIST works the same on the Cray, CDC, and Sun computers, but does not work on the Iris workstation. For the Iris, 
the two lines reading and writing the NAMELIST were replaced by calls to an input subroutine, and an output subroutine. This change to the $\mathrm{K}-\mathrm{FIX}(\mathrm{GT})$ source only changes two lines at the beginning of the program, and adds two subroutines to be linked in during compilation. The function that returns a CPU time is different on each machine, this was solved by providing a function that matches the CDC function for its name and arguments, but calls the local version of the SECOND function. This function is generally kept in another file, and linked in when compiling. This adjustment of the SECOND function does not require any changes to the main source code for K-FIX(GT).

The following lines have sample commands to compile and run K-FIX(GT) on each computer. The output files would go to whatever the default is for that computer. A real run would probably use the computers batch or queue system.

\section{CDC (running NOS/VE):}

$f \operatorname{tn} i=k f i x_{-} f b=k f i x$

exet kfix $p=$ 'input=inpa1'

Cray (running UNICOS):

cft77 secondc.f

cft77 kfix.f

segldr -o kfix kfix.o secondc.o

kfix < inpa1

Iris:

$f 77$-o kfix kfixi.f secondi.f readin.f

kfix $<$ inpa1

Sun:

$f 77$-o kfix kfix.f second.f

kfix $<$ inpa 1 


\section{Chapter 4}

\section{K-FIX(GT) Output}

\subsection{Introduction}

K-FIX(GT) originally had two forms of output, text files with huge amounts of data in a format which was hard to comprehend, and DISSPLA graphic output. The graphs consisted of vector and contour plots of data from a 2 dimensional slice of the three dimensional region being simulated. An additional form of graph is now supported, plots of quantities at fixed locations as a function of time can be requested.

When K-FIX(GT) arrived at the Georgia Institute of Technology, graphics output was an integral part of the program. This led to a dependence on the type and version of graphics libraries available on a system on which the user wished to run K-FIX(GT). There was an additional problem with all the graphic output being lost if K-FIX(GT) crashed due to an error. When a decision was made to do the computation on a Cray XMP $/ 48^{1}$, the graphics dependent subroutines were separated into separate programs that read data files output by K-FIX(GT).

The output files can be quite large (100's of megabyte for a large run). It is recommended that some form of file compression be used when the files are not being used. The Unix compress utility can compress the ASCII data files by up to a factor of six, and compresses binary files by up to a factor of two.

In the following sections, the various output files produced by K-FIX(GT) are described.

\footnotetext{
${ }^{1}$ Supported by the NCSA at the University of Illinois.
} 


\subsection{TAPE9}

Tape9 refers to the default file connected to fortran unit 9. Each computer has a different way to connect this to a specific file, but a simpler way to work is to use the default, and rename it to whatever the user likes after each run. Tape 9 holds a large variety of information, and is not meant to be read in by another program.

The first item in tape9 is a copy of what K-FIX(GT) reads as input fr. ... the standard input. This is occasionally useful to determine if inputs are being read correctly. The next section of tape 9 is a formatted repeat of the input data, with more description of each variable. The third section is an output of the content of the flag arrays. Based on the input, flags are calculated for each cell.

The final section of tape9 is output repeatea for each cycle. The first line for each cycle consists of a set of variables giving information on thit cycle. These variables are:

ITER

'TIME

D'T

CYCLE

CP

GRINDS
The number of iterations for that cycle.

The time of the end of the cycle.

The time step used for that cycle.

The cycle number.

The cumulative CPU time of the run.

CPU time for this cycle / \# of cells.

The program also makes a note if it has written a restart file. At times determined by TPR, a full print of all the cell quantities over a subregion specified by IP1, IP2, JP1, JP2, KP1, and KP2 is made. This is not a format that is suited for reviewing the progress of tho simulation, but can be used to spot check particular quantities.

\subsection{TAPE15}

Tape15 refers to the unformatted ( binary) file that holds the information necessary to restart a K-FIX(GT) run. This file cannot be used on a computer other that the one used to create it ( unless you translate to ASCII, transfer, then translate back into binary). This does not hold all variables, only the necessary ones, the others are recalculated upon restart.

In some cases, the recalculation of some variables is enough to restabilize 
a run that stopped due to too many iterations.

\subsection{TAPE70}

Tape70 refers to a file used to store the data used for 1 dimensional plots ( quantity vs. time). Further discussion of the plotting programs can be found in the graphics chapter.

For tape70 and tape77, another decision has to be made, whether to use formatted ( ASCII) or unformatted ( binary). ASCII has a few advantages, such as increased readability, easy transfer from one computer to another, and ability to use a language other than fortran to read in the data files. Binary also has its advantages, such as having approximately half the file size of the ASCII version, full computer precision for the numbers ( not rounded off to 5 digits), and considerably faster reading and writing of the data. The first application after separating the graphics involved making the runs on a Cray, and the plots on a Cyber, so the ease of transfer made us pick ASCII. For other situations binary is clearly superior; a number of translation programs are mentioned in the graphics chapter.

Tape70 files are created by the following write statements, and can be read into the graphics programs using similar read statements. The variables are explained in Appendix A.

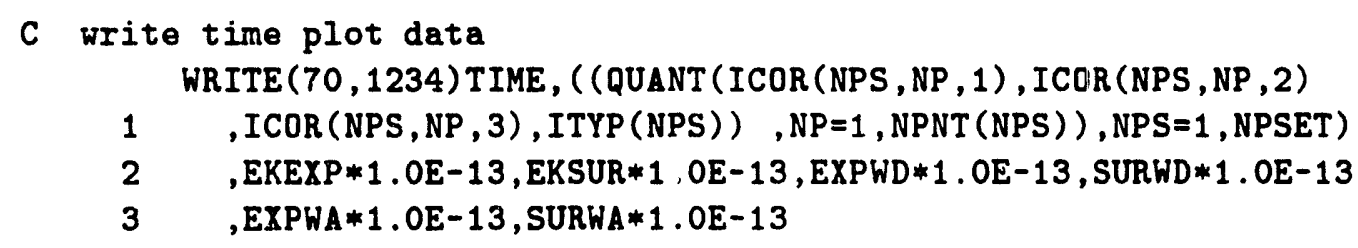

A run is frequently divided up into multiple runs, with restarts. When the program restarts, the output files are restarted as new files. The files cannot be directly appended to each other because there may be a repetition of the output data for one or two steps. For tape70 files, the first set of data from each of the restart runs needs to be deleted, it is a duplication of the last set of data from the previous run. If a run ends with a stop due to too 
many iterations, the data set for the last time step is erroneous and should be deleted. The data set can be deleted manually, using a text editor.

\subsection{TAPE77}

Tape 77 refers to a file used to store the data used for 2 dimensional plots ( vector, lagrangian, and contour). Further discussion of the plotting programs can be found in the graphics chapter.

Tape 77 files are created by the following write statements, and can be read into the graphics programs using similar read statements. The variables are explained in Appendix A.

C write vector information ( IKIND $=1$ or 2 )

WRITE $(77,1235)$ IKIND , ISURF , JSURF , KSURF , TIME , CYCLE , III , JJ J , SIGNAL WRITE $(77,1234)((0.5 *$ (UG (I J, KSURF ) +UG $(I-1, J, K S U R F))$

1

, $0.5 *(V G(I, J, K S U R F)+V G(I, J-1, K S U R F))$

2

$$
, I=2, I I I+1), J=2, J J J+1)
$$

C write lagrangian marker locations ( IKIND $=3$ )

WRITE $(77,1235)$ IKIND , ISURF, JSURF , KSURF, TIME, CYCLE , III , JJJ , SIGNAL

$\operatorname{WRITE}(77,1234)(C Q(I C Q, 1,1), I C Q=1$, III $)$

C write contour plot information.

WRITE $(77,1235)$ IKIND , ISURF, JSURF , KSURF, TIME , CYCLE , III , JJJ , SIGNAL

WRITE $(77,1234)$ ( ( QUANT ( $I, J, K S U R F, I K I N D), I=2, I I I+1), J=2, J J J+1)$

1234 FORMAT ( $1 \mathrm{P}, 8 \mathrm{E} 10.3)$

1235 FORMAT $(4(2 X, I 4), 2 X, 1 \mathrm{PE} 14.7,3(2 \mathrm{X}, \mathrm{I} 6), 2 \mathrm{X}, \mathrm{A} 8)$

When a tape77 file is divided due to restarts, the last set of data on a run that ends in too many iteration is erroneous and should be deleted. 


\section{Chapter 5}

\section{Graphics}

\subsection{Introduction}

The graphics-dependent subroutines of K-FIX(GT) were separated into two additional programs, TWOD and TMPLT. In addition to these two programs, there are many other programs to process and manipulate the data from tape70 and tape77. Since separating the graphics, we have run K-FIX(GT) on a Cray supercomputer, Cyber mainframes, IRIS workstations, and Sun workstations while producing the graphics output on Sun workstations ( PVI $\left.{ }^{1}\right)$, IRIS workstations ( animations), and Cyber mainframes running NOS/VE ( DISSPLA ${ }^{2}$ ).

\subsection{Time Plots}

Time plots are currently being produced on a Cyber 855 mainframe using DISSPLA, and on a SPARCstation1 using PVI. The original software developed using DISSPLA is currently incorporated into the program TMPLT. The time plot software has been rewritten to use the PVI graphics libraries; it is included as the program TP. The PVI graphics routines allow the user to review the results of a run as soon as it is completed, by viewing them on the workstation's screen. The operating speed of this program is greatly enhanced by the use of binary data format. PVI will also allow the printing of the plots

\footnotetext{
${ }^{1}$ Precision Visuals Inc. fortran graphics libraries.

${ }^{2}$ Display Integrated Software System and Plotting LAnguage, by Integrated Software Systems Corporation.
} 
on a postscript laser printer, with potential inclusion in reports as a postscript image. There is a general purpose plotting program, called PLOTGENERAL, and a program to extract tape70 data for the PLOTGENERAL program. The various programs for producing time plots are described below.

\section{TMPLT Program}

TMPLT produces plots of a chosen variable at a particular set of locations as a function of time. TMPLT is written using DISSPLA graphics routines for a Cyber mainframe. TMPLT produces output for printing on the local Xerox laser printers, plotters, or viewing on a graphics terminal.

\section{Input}

TMPLT reads the data from the tape70 file, and gets some necessary information from an input file based on the input file for K-FIX(GT). A sample input file follows:

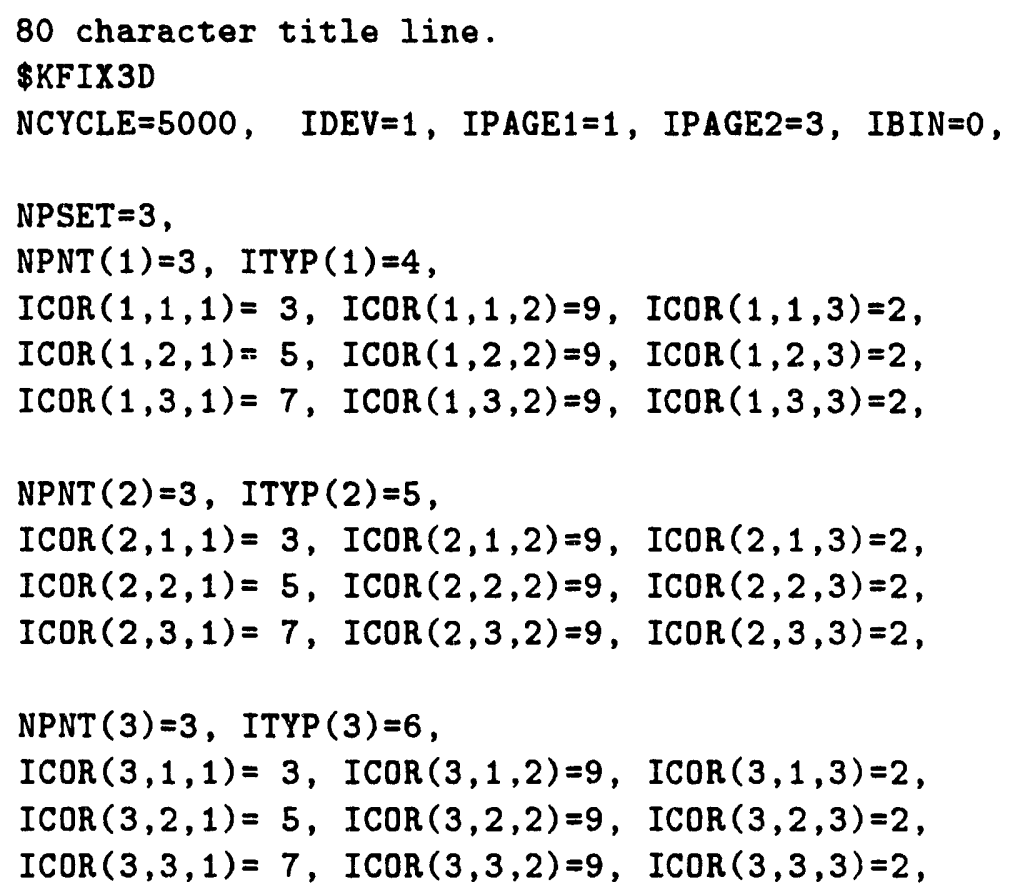


\$END

The input file consists of a title line, five control variables, and the descriptions of the requested plots taken directly from the K-FIX(GT) input file. The five new variables are:

NCYCLE Maximum number of time points for this run, can be greater than the actual number.

IPAGE1 Start at plot numbered IPAGE1.

IPAGE2 End at plot numbered IPAGE2, allows printing of a subset of the plots.

IDEV Device number for output. Selects format of graphic output. $0=$ epic format ( default), $1=$ calcomp format.

IBIN $\quad 0=$ if binary version of tape70 does not exist ( it will be created), 1 = if binary version of tape70 already exists ( as tape71).

The input file is read from the standard input, tape70 or tape71 are read from files of that name.

\section{Compile and Run}

The DISSPLA libraries must be available to link with the fortran source, and the appropriate data files must also be available in order to run the program. TMPLT produces an output file of the format chosen by IDEV, which can be sent to a printer of viewed on a graphics terminal. Sample commands to compile and run the programs on the Georgia Tech Cybers are:

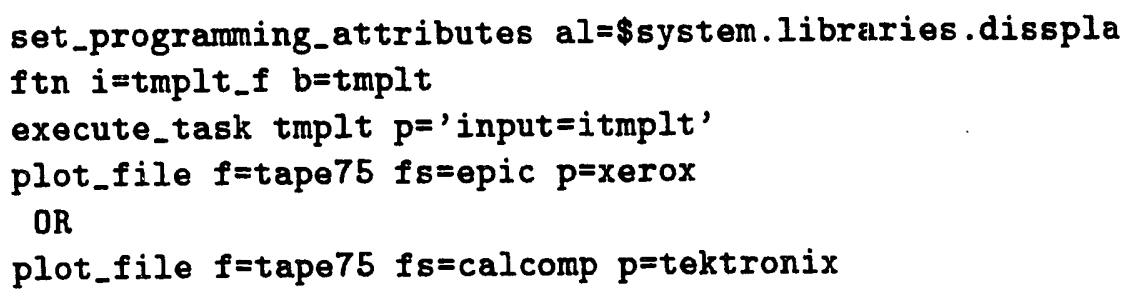

\section{TMTHIN Program}

TMTHIN extracts one or more sets of data from a tape70 file, trims out excess data points to reduce the size of the files, and then writes it to a file for use by the PLOTGENERAL program. The thinning method passes through the 
data and tests every other point against its neighbors. TMTHIN eliminates the middle point if a straight line passing from the left to the right point passes sufficiently close to the middle point (limit determined by EPS). TMTHIN currently runs on the Sun workstation.

\section{Input}

TMTHIN reads data from the tape70 file and its input file, and sends the full data to tape80, and the thinned data to tape88. A sample input for TMTHIN:

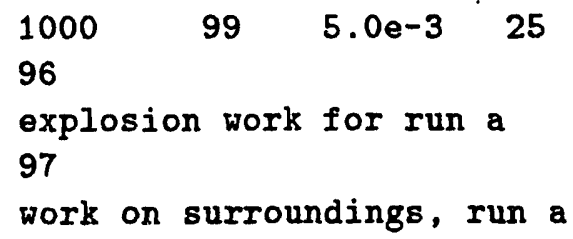

The variables on the first line are NCYCL, NDAT, EPS, and NTHIN. Subsequent lines are pairs of NTH, and NAME repeated as many times as you want to extract a set of data.

NCYCL Number of time cycles to be read.

NDAT Number of data points for each time step ( not including the time itself).

EPS Thinning tolerance, $0=$ no thinning.

NTHIN Maximum number of thinning passes through the data, 0 $=$ no thinning. The program stops when NTHIN passes are completed, or no more data points can be eliminated.

NTH Number of the data points requested $(1 \leq N T H \leq$ $N D A T)$.

NAME Text string describing data.

\section{Compile and Run}

Sample commands to compile and run this program on the Sun workstation follow:

177 -o tmthin tmthin.f tmthin < inpthin 


\section{PLOTGENERAL Program}

The PLOTGENERAL program is a general purpose plotting program, that uses DISSPLA routines and runs on the Cyber mainframes. TMTHIN extracts and reformat tape70 data for use by PLOTGENERAL. Data from separate $\mathrm{K}-\mathrm{FIX}(\mathrm{GT})$ runs may be combined and shown on the same plot. PLOTGENERAL also allows the use of $\log$ axes, and custom legends for each line to be plotted.

\section{Input}

PLOTGENERAL reads all of it's input from the standard input, and produces it's output in a file called tape9. Sample input for PLOTGENERAL:

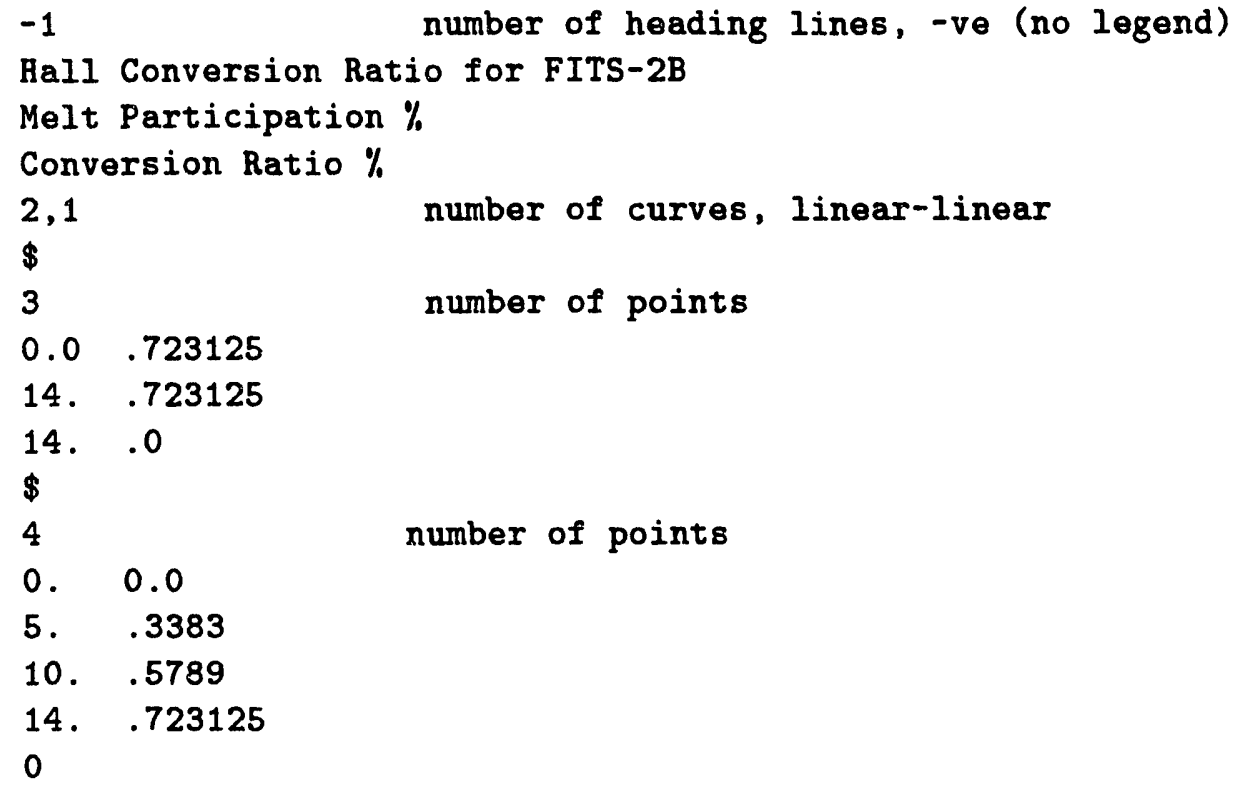

The first line is NHL followed by a comment. The next NHL lines are the title lines of the plot, followed by the $x$-axis title and the $y$-axis title. The next line has NCURVE and ISTYLE, followed by comments. The next line has NCURVE and ISTYLE. The next has the line's legend text, the end of the legend text is marked by a $\$$. The next has NC. This is followed by NC lines holding $\mathrm{X}$ and $\mathrm{Y}$ values. This is followed by legend, NC, X's, and Y's for all the lines. The final line allows the program to begin another plot ( if 
NHL $\neq 0$ ).

NHL the absolute value of NHL is the number of title lines for the plot, if NHL is negative, then the program doesn't produce any legends. If $\mathrm{NHL}=0$, then the program quits.

HTITL1,2,3 the first, second, and third titles for the plot ( as many as required by $\mathrm{NHL}$ ).

XTITLE the $\mathrm{x}$-axis title for the plot.

YTITLE the $y$-axis title for the plot.

NCURVE the number of curves on the plot.

ISTYLE the axis style for the plot, $1=$ linear-linear, $2=\log -\log$, $3=$ linear-log, $4=\log$-linear.

LEGS(n) the legend for curve $n$.

$\mathrm{NC}$ the number of points for the curve.

$X(n, i) \quad x$ value for the point $i$ of the curve $n$.

$Y(n, i) \quad y$ value for the point $i$ of the curve $n$.

\section{Compile and Run}

The DISSPLA libraries must be available to link with the fortran source code. The program can be run interactively, and all input is read in from the standard input. Output is produced in EPIC format and printed on the Xerox laser printers. Sample commands to compile and run the program on the Georgia Tech Cybers are:

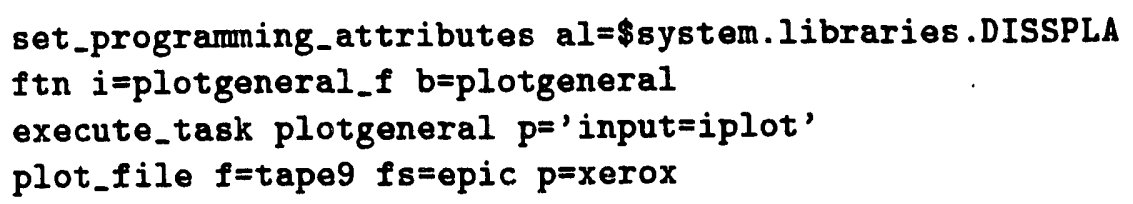

\section{TP Program}

The TP program was written on a Sun workstation running SunView, and uses fortran 77 and the PVI graphics subroutines. At the present time, it is only used to preview time plots on the workstations screen. The software is easily modified to produce a postscript file as output, which can be printed or included in documents. 


\section{Input}

TP reads from a file called tpdat, which is a binary tape70, an input file ( at standard input), and also interacts through a mouse with the user. The user can view the plots ( with a few seconds delay to process the data), and place the legend in an empty spot. The following listing is an input file for TP.

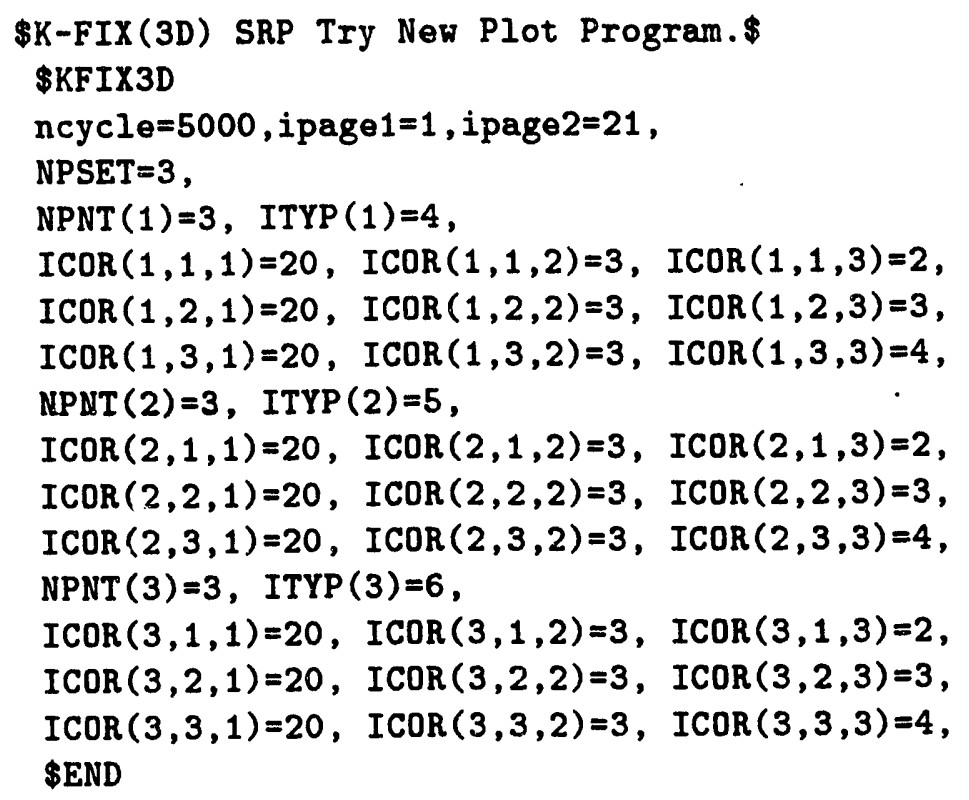

The first line is the title for the plots. The PVI routines mark the beginning of a text string with any character, and the end with a matching character, this allows them to properly justify the text. The following variables are read in by a namelist. The first three are control variables, the rest come from the $\mathrm{K}$-FIX(GT) input file.

NCYCLE Maximum number of time steps to read.

IPAGE1 Start with plot number IPAGE1.

IPAGE2 Stop at plot number IPAGE2.

\section{Compile and Run}

The PVI libraries must be available to compile this program. PVI supplies a command, di3load which compiles the fortran program with the appropriate routines and device drivers. The program opens up a SunView window for the screen previewing. The mouse is used the position the legend, and proceed 
to the next graph. The middle button on the mouse relocates the legend to the cursor's position, any other button goes on to the next graph. Sample commands to compile and run the program on a Sun workstation are:

di3load su3 $-G M-o$ tp tp.f

tp $<$ inptp

\section{TPA2B Program}

TPA2B is a program that converts a tape70 file into a binary file. The output file is used as input for TP, and may have less cycles than the original tape70 file.

\section{Input}

TPA2B take exactly the same input as TP on the standard input, and reads data from tape70. TPA2B only produces output for the first NCYCLE cycles, the rest are not written to the output file.

\section{Compile and Run}

This program is just plain fortran, and will run on any computer, but it's output may be machine dependent. Sample commands to compile and run the program on a Sun workstation are:

$f 77$-o tpa2b tpa2b.f

tpa2b $<$ inptp

\subsection{Two Dimensional Plots}

Two dimensional plots have been produced on the Cyber using DISSPLA The DISSPLA version of the plotting code is called TWOD. The two dimensional plotting program has not yet been ported to the PVI graphics package. These plots provide an understandable means of viewing the output of a K-FIX(GT) run. The data takes the form of contour plots, vector plots, and lagrangian plots on paper or graphics terminals. 


\section{TWOD Program}

TWOD was written using DISSPLA subroutines to show the data from a two dimensional slice of the three dimensional simulation region. The program can send output to either a graphics terminal or printer. Different properties are plotted in different ways. Velocity plots are made by placing a vector representing the magnitude and direction of the velocity into each cell. Contour plots are made for most other properties of interest, such as pressure, void fraction, temperatures, etc. Contour plots show the constant value contours for the slice being plotted. The final type of plot shows the location of the lagrangian markers with individual dots. The lagrangian markers show the expansion of the explosion zone.

\section{Input}

The TWOD plot program reads the data from the tape 77 file, and gets some necessary information from an input file based on the K-FIX(GT) input file. A sample input file follows:

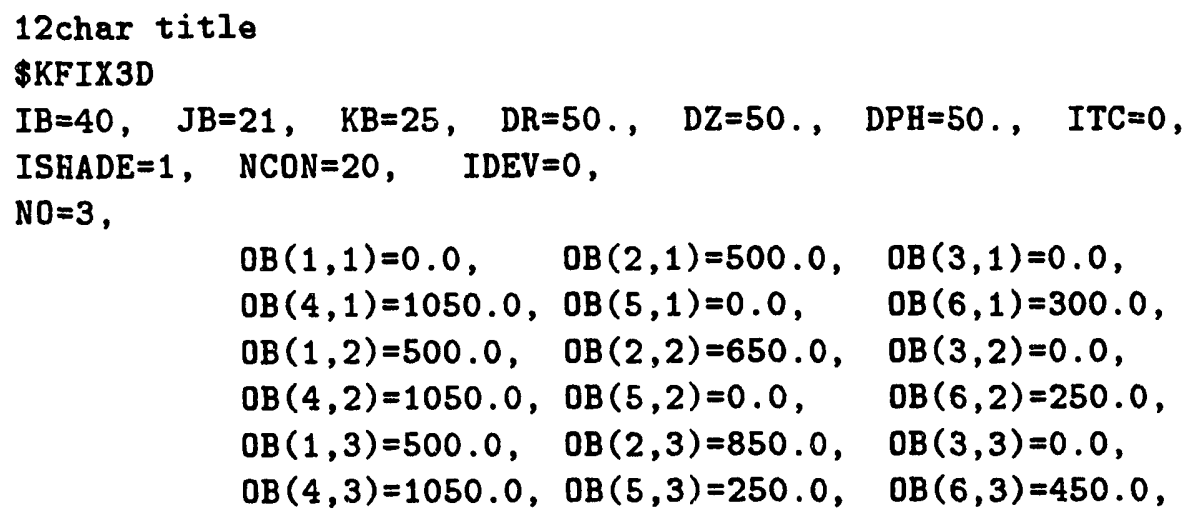

The input file consists of the title line, seven information variables, three control variables, and the descriptions of the obstacles. IB is equal to IB2 - 2, simila equations hold for JB and KB. Everything except the control variables is takel directly from the $\mathrm{K}$-FIX(GT) input file. The three new variables are: 
ISHADE Controls whether to shade obstacle, or leave empty, empty is faster and cheaper for CPU time.

NCON The number of contour lines to put on graph.

IDEV Device number for output. Selects format of graphic output. 0 = epic format ( default), $1=$ calcomp format.

\section{Compile and Run}

The program reads it's data from unit 77 , and the input file from the standard input. Sample commands to compile and run the program are:

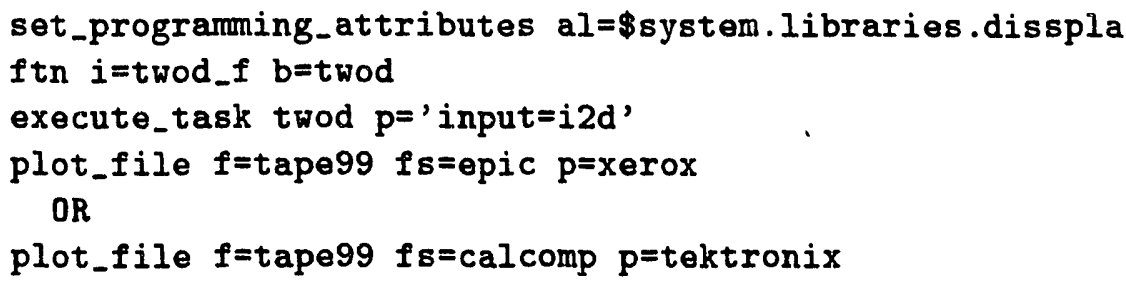

\section{TWODSLCT Program}

TWODSLCT is a secondary program to prepare the tape77 file for plotting. This program allows the user to extract data of a particular type, and times from the tape77 data file. Then TWOD is run on the new tape77 file.

\section{Input}

TWODSLCT reads it's input from tape66 and an input file at the standard input, and writes it's output to tape88. A sample input for TWODSLCT follows:

$600 ., 100 ., 1000 ., 5,0,0,2$

These numbers are TBEGIN, TSTEP, TEND, IIKIND, IISURF, JJSURF, and KKSURF.

TBEGIN Beginning time for plots ( $\mathrm{msec}$ ).

TSTEP Time interval between plots ( $\mathrm{msec}$ ).

TEND Final time for plots ( $\mathrm{msec}$ ).

IIKIND Type of data requested ( as in input for K-FIX(GT)).

II, JJ, KKSURF Two zeros, and one integer for height of plot along I, J, or $\mathrm{K}$ axis ( as in input for K-FIX(GT)). 


\section{Compile and Run}

This program does not depend on DISSPLA routines, and can be run on any machine. This is a sample run on a Cyber, including plotting with TWOD.

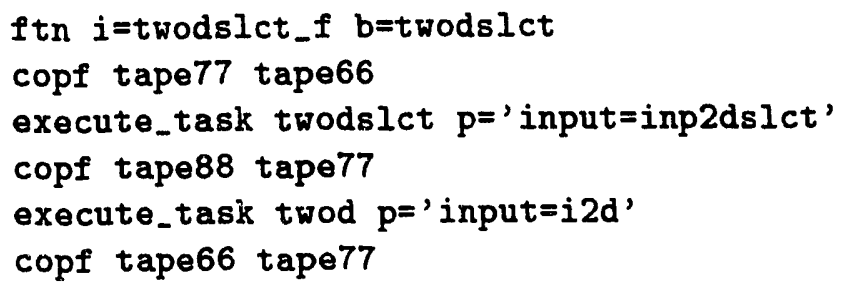

\subsection{Computer Animations}

A program was written to provide a computer animation of the pressure and void fraction data from tape77. The program, ANIM, was written on an Iris workstation using the Iris graphic subroutines. There are two programs to prepare the tape77 file for the ANIM program.

\section{ANIM Program}

ANIM uses the same data as the contour plots, but adds lagrangian markers. Color is used to represent the value of the data, with a scale that adjusts depending on the current maximum. This output is suitable for video taping, and provides a better understanding of the overall condition of the explosion as time progresses.

\section{Input}

ANIM reads from binary tape77 files, and an input file on standard input. The binary tape77 files are assumed to be called anim.datx, where $x$ is a sequence of numbers to allow multiple input files ( consecutive times for the data). A sample input file for ANIM follows:

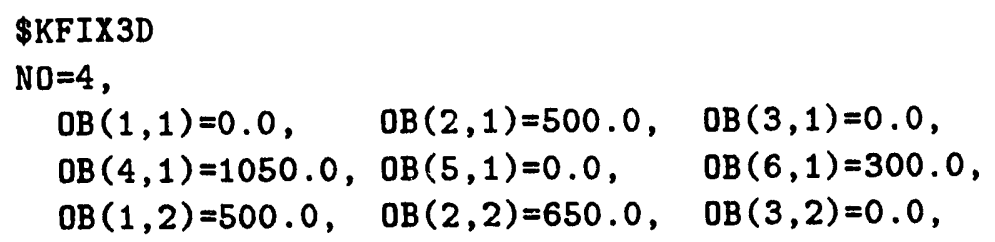




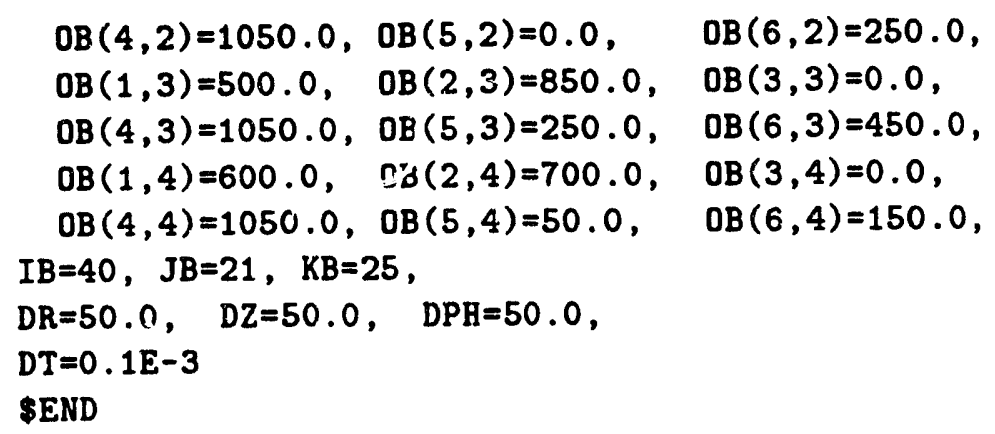

This fite just consists of a subset of the K-FIX(GT) input file describing the obstacles and spatial and time steps. The data comes from a file that holds only the data io be used for the current animation run.

\section{Compile and Run}

This profram is compiled and run on an IRIS graphics workstation. The workstation has 24 bits of color, and is double buffered to make the animation smoother. The speed is limited to approximately 12 frames per second by the speed of retrieving data from the workstation's hard disk. This program uses

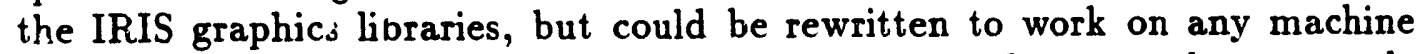
with the needed graphics hardware. The following set of commands are sample commands for the IRIS.

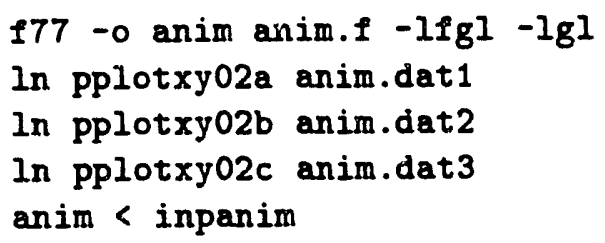

\section{PREPROC Program}

The PREPROC program spits a tape77 files into many files, each holding the data needed for une animation run. Each output file holds either pressure or void fraction for one slice, plus the lagrangian markers for that slice. PREPROC, was written to run on the Cybers, since at the time that was where the data was stsred. The program is in fortran 77 and can easily be compiled and run on another machine. 


\section{Input}

PREPROC reads from tape77, and produces all the output files that it can. There is not input file, all the information needed is in the tape7 7 file.

\section{Compile and Run}

The output of PREPROC consists oi multiple files with names of the form $x P L O T y y z z . X$ is replaced by a $p$ for pressure data or a $v$ for void fraction data. $Y Y$ is replaced by $x y$ for a plot in the $x y$ plane, $x z$ for the $x z$ plane, or yz for the yz plane. $\mathrm{ZZ}$ is replaced by a two digit number showing the height of the cross section, $\mathrm{zz}=01$ is a border cell, so $\mathrm{zz}=02$ is the first cell in the simulation region. The following are a set of commands to compile and run the program on a Cyber mainframe:

Itn $i=p r e p r o c \_f$ bepreproc

execute_task preproc $p='$ input=tape77'

\section{TXT2BN Program}

TXT2BN is a small program to convert an ASCII tape77 file into a binary tape77 file.

\section{Input}

TXT2BN asks for an input filename and an output filename. It is simplest to run it interactively.

\section{Compile and Run}

The following commands compile and run TXT2BN, including the program's prompts for the user to input the filenames.

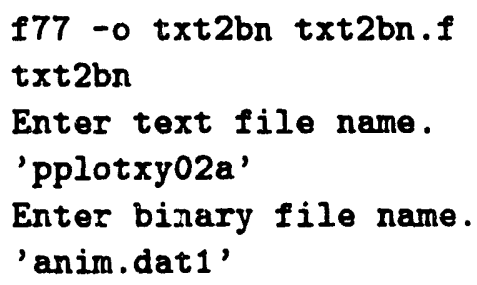




\section{Bibliography}

[1] W. C. Rivard and M. D. Torrey. K-FIX: A computer program for transient, two-dimensional, two-fluid flow. Technical Report LA-NUREG-6623, Los Alamos National Lab, April 1977.

[2] W. C. Rivard and M. D. Torrey. K-FIX: A computer program for transient, two-dimensional, two-fluid flow - THREED: An extension of the K-FIX code for three-dimensional calculations. Technical Report LA-NUREG6623, Suppl. II, Los Alamos National Lab, January 1979.

[3] Y. M. Farawila, S. I. Abdel-Khalik, and P. J. Halvorson. Numerical modelling of the expansion phase of steam explosions. Part I: Method and validation. Technical Report GTRSR - 006, Georgia Institute of Technology, Nuclear Engineering Program, June 1990.

[4] Y. M. Farawila, S. I. Abdel-Khalik, and P. J. Halvorson. Numerical modelling of the expansion phase of steam explosions. Part II: Application to the savannah river plant. Technical Report GTRSR - 007, Georgia Institute of Technology, Nuclear Engineering Program, June 1990. 


\section{Appendix A}

\section{K-FIX(GT) Variables}

The FORTRAN variables that appear in COMMON storage, or are used for input data are defined here in alphabetical order. The input data have been defined in detail in the chapter on the input to K-FIX(GT).

Table A.1: K-FIX(GT) variable list.

\begin{tabular}{l|c|l} 
Fortran Symbol & $\begin{array}{c}\text { Algebraic } \\
\text { Symbol }\end{array}$ & Definition \\
\hline ABETA(I,J,K) & $\left(\frac{d D_{i, j, k}}{d P_{i, j, k}}\right)^{-1}$ & $\begin{array}{l}\text { Reciprocal derivative of the D function } \\
\text { (liquid or gas continuity equation) with } \\
\text { respect to pressure computed in subrou- } \\
\text { tines BETAS and ITER. } \\
\text { NO LONGER IN USE. Replaced by } \\
\text { computation on demand when needed. } \\
\text { Interfacial surface area per unit of mix- } \\
\text { ture volume. Computed in subroutine } \\
\text { ASURFS. } \\
\text { Storage for the coefficients of analytic } \\
\text { fits to the liquid and gas equation of } \\
\text { state data. Also used for intermedi- } \\
\text { ate storage of computed state proper- } \\
\text { ties. Initialized in subroutine SETC. }\end{array}$
\end{tabular}


Table A.2: Continuation of the K-FIX(GT) variable list.

\begin{tabular}{|c|c|c|}
\hline Fortran Symbol & $\begin{array}{l}\text { Algebraic } \\
\text { Symbol }\end{array}$ & Definition \\
\hline CDEB & $c_{\text {deb }}$ & Input. \\
\hline $\mathrm{CG}(\mathrm{I}, \mathrm{J}, \mathrm{K})$ & $\left(c_{g}\right)_{i, j, k}$ & $\begin{array}{l}\left(\partial I_{g} / \partial T_{g}\right)_{p}, \text { computed in subroutine } \\
\text { EOSG. }\end{array}$ \\
\hline $\mathrm{CL}(\mathrm{I}, \mathrm{J}, \mathrm{K})$ & $\left(c_{l}\right)_{i, j, k}$ & $\begin{array}{l}\left(\partial I_{l} / \partial T_{l}\right)_{p}, \text { computed in subroutine } \\
\text { EOSL. }\end{array}$ \\
\hline $\operatorname{CONV}(\mathrm{I}, \mathrm{J}, \mathrm{K})$ & - & $\begin{array}{l}\text { Pressure iteration convergence criteria. } \\
\text { Computed in subroutine BETAS. }\end{array}$ \\
\hline $\mathrm{CQ}(\mathrm{I}, \mathrm{J}, \mathrm{K})$ & - & $\begin{array}{l}\text { Temporary storage array used for } \\
\text { plotting. }\end{array}$ \\
\hline CRATE $(\mathrm{I}, \mathrm{J}, \mathrm{K})$ & $\left(J_{c}\right)_{i, j, k}$ & $\begin{array}{l}\text { NO LONGER IN USE. Replaced by us- } \\
\text { ing ERATE for both evaporation and } \\
\text { condensation. }\end{array}$ \\
\hline CYCLE & - & Input. \\
\hline D1 & - & $\begin{array}{l}\text { Value of DG or DL corresponding to } \\
\text { pressure } P_{1} \text {. Used in subroutine NEWP } \\
\text { together with D2 and D3 to estimate } \\
\text { the advanced time pressure. }\end{array}$ \\
\hline D2 & - & $\begin{array}{l}\text { Value of } \mathrm{DG} \text { or } \mathrm{DL} \text { corresponding to } \\
\text { pressure } P_{2} \text {. }\end{array}$ \\
\hline D3 & - & $\begin{array}{l}\text { Value of DG or DL corresponding to } \\
\text { pressure } P_{3} \text {. }\end{array}$ \\
\hline $\mathrm{DA}(\mathrm{I})$ & - & \\
\hline DEBRAD & - & Input. \\
\hline $\mathrm{DG}$ & $D_{g}$ & $\begin{array}{l}\text { The amount by which the gas continu- } \\
\text { ity equation differs from exactly zero. } \\
\text { Computed in subroutine DGAS. }\end{array}$ \\
\hline DL & $D_{l}$ & $\begin{array}{l}\text { The amount by which the liquid conti- } \\
\text { nuity equation differs from exactly zero. } \\
\text { Computed in subroutine DLIQ. }\end{array}$ \\
\hline $\mathrm{DPH}$ & $\delta \phi$ & Input. \\
\hline DR & $o r$ & Input. \\
\hline
\end{tabular}


Table A.3: Continuation of the K-FIX(GT) variable list.

\begin{tabular}{|c|c|c|}
\hline Fortran Symbol & $\begin{array}{c}\text { Algebraic } \\
\text { Symbol }\end{array}$ & Definition \\
\hline $\mathrm{DT}$ & $\delta t$ & Input. \\
\hline DTODA & $\frac{\delta t}{\delta \phi}$ & $\begin{array}{l}\text { Ratio of the time step to the cell's az- } \\
\text { imuthal dimension. }\end{array}$ \\
\hline DTODR & $\frac{\delta t}{\delta r}$ & $\begin{array}{l}\text { Ratio of the time step to the cell's radial } \\
\text { dimension. }\end{array}$ \\
\hline DTODZ & $\frac{\delta t}{\delta z}$ & $\begin{array}{l}\text { Ratio of the time step to the cell's axial } \\
\text { dimension. }\end{array}$ \\
\hline DTORBDP(I) & $\frac{\delta t}{r_{i+\frac{1}{2}} \delta \phi}$ & $\begin{array}{l}\text { The time step divided by the product of } \\
\text { the radius of the cell's outer boundary } \\
\text { and the cell's azimuthal dimension. }\end{array}$ \\
\hline DTORBDR(I) & $\frac{\delta t}{r_{i+\frac{1}{2}}^{\delta r}}$ & $\begin{array}{l}\text { The time step divided by the product of } \\
\text { the cell's radial dimension and the ra- } \\
\text { dius of the cell's outer boundary. }\end{array}$ \\
\hline DTORDPH(I) & $\frac{\delta t}{r_{i} \delta \phi}$ & $\begin{array}{l}\text { The time step divided by the product } \\
\text { of the radius of the cell center and the } \\
\text { cell's azimuthal dimension. }\end{array}$ \\
\hline DTORDR(I) & $\frac{\delta t}{r_{i} \delta r}$ & $\begin{array}{l}\text { The time step divided by the product of } \\
\text { the cell's radial dimension and the ra- } \\
\text { dius of the cell center. }\end{array}$ \\
\hline $\mathrm{DZ}$ & $\delta z$ & Input. \\
\hline EGFA & - & $\begin{array}{l}\text { Flux of gas internal energy across the } \\
\text { aft boundary of cell } i, j, k \text {. Computed } \\
\text { in subroutine SIEGF. }\end{array}$ \\
\hline $\operatorname{EGFB(I)}$ & - & $\begin{array}{l}\text { Flux of gas internal energy across the } \\
\text { bottom boundary of cell } i, j, k \text {. Com- } \\
\text { puted in subroutine SIEGF. }\end{array}$ \\
\hline $\operatorname{EGFF(I,J)}$ & - & $\begin{array}{l}\text { Flux of gas internal energy across the } \\
\text { fore boundary of cell } i, j, k \text {. Computed } \\
\text { in subroutine SIEGF. }\end{array}$ \\
\hline EGFL & - & $\begin{array}{l}\text { Flux of gas internal energy across the } \\
\text { left boundary of cell } i, j, k \text {. Computed } \\
\text { in subroutine SIEGF. }\end{array}$ \\
\hline
\end{tabular}


Table A.4: Continuation of the K-FIX(GT) variable list.

\begin{tabular}{|c|c|c|}
\hline Fortran Symbol & $\begin{array}{c}\text { Algebraic } \\
\text { Symbol } \\
\end{array}$ & Definition \\
\hline EGFR & - & $\begin{array}{l}\text { Flux of gas internal energy across the } \\
\text { right boundary of cell } i, j, k \text {. Computed } \\
\text { in subroutine SIEGF. }\end{array}$ \\
\hline EGFT & - & $\begin{array}{l}\text { Flux of gas internal energy across the } \\
\text { top boundary of cell } i, j, k \text {. Computed } \\
\text { in subroutine SIEGF. }\end{array}$ \\
\hline EKEXP & & Kinetic energy of the expansion zone. \\
\hline EKSUR & & Kinetic energy of the surrounding zone. \\
\hline ELFA & - & $\begin{array}{l}\text { Similar to EGFA, except for the liquid. } \\
\text { Computed in subroutine SIELF. }\end{array}$ \\
\hline ELFB(I) & - & $\begin{array}{l}\text { Similar to EGFB(I), except for the liq- } \\
\text { uid. Computed in subroutine SIELF. }\end{array}$ \\
\hline $\operatorname{ELFF}(\mathrm{I}, \mathrm{J})$ & - & $\begin{array}{l}\text { Similar to EGFF(I,J), except for the liq- } \\
\text { uid. Computed in subroutine SIELF. }\end{array}$ \\
\hline ELFL & - & $\begin{array}{l}\text { Similar to EGFL, except for the liquid. } \\
\text { Computed in subroutine SIELF. }\end{array}$ \\
\hline ELFR & - & $\begin{array}{l}\text { Similar to EGFR, except for the liquid. } \\
\text { Computed in subroutine SIELF. }\end{array}$ \\
\hline ELFT & - & $\begin{array}{l}\text { Similar to EGFT, except for the liquid. } \\
\text { Computed in subroutine SIELF. }\end{array}$ \\
\hline $\operatorname{ERATE}(\mathrm{I}, \mathrm{J}, \mathrm{K})$ & $J_{e}$ & $\begin{array}{l}\text { Evaporation rate computed in subrou- } \\
\text { tine MASSX. MASSX replaces the orig- } \\
\text { inal BOIL and COND. }\end{array}$ \\
\hline EXPWA & - & $\begin{array}{l}\text { Explosion work, computed using the } \\
\text { pressure in the explosion zone and the } \\
\text { average of } \theta \text { 's just inside and outside } \\
\text { the interface. Computed in subroutine } \\
\text { WORK. }\end{array}$ \\
\hline EXPWD & - & $\begin{array}{l}\text { Explosion work, computed using the } \\
\text { pressure in the explosion zone and the } \\
\text { donor cell } \theta \text {. Computed in subroutine } \\
\text { WORK. }\end{array}$ \\
\hline FDRG & - & Input. \\
\hline
\end{tabular}


Table A.5: Continuation of the K-FIX(GT) variable list.

\begin{tabular}{|c|c|c|}
\hline Fortran Symbol & $\begin{array}{l}\text { Algebraic } \\
\text { Symbol }\end{array}$ & Definition \\
\hline$\overline{\text { FHEAT }}$ & - & Input. \\
\hline $\mathrm{FL}(\mathrm{I}, \mathrm{J}, \mathrm{K})$ & - & Integer cell flags. \\
\hline FLO(M) & - & Input. \\
\hline FLOA $(M)$ & - & Input. \\
\hline FMASS & - & Input. \\
\hline GRAV & $g$ & Input. \\
\hline HFGA & - & $\begin{array}{l}\text { Heat flux across the aft boundary of cell } \\
\mathrm{i}, \mathrm{j}, \mathrm{k} \text { for the gas due to conduction, } \\
\text { computed in subroutine HEATCG. }\end{array}$ \\
\hline HFGB & - & $\begin{array}{l}\text { Heat flux across the bottom bound- } \\
\text { ary of cell } i, j, k \text { for the gas due } \\
\text { to conduction, computed in subroutine } \\
\text { HEATCG. }\end{array}$ \\
\hline HFGF & - & $\begin{array}{l}\text { Heat flux across the fore boundary of } \\
\text { cell } i, j, k \text { for the gas due to conduction, } \\
\text { computed in subroutine HEATCG. }\end{array}$ \\
\hline HFGL & - & $\begin{array}{l}\text { Heat flux across the left boundary of cell } \\
\mathrm{i}, \mathrm{j}, \mathrm{k} \text { for the gas due to conduction, } \\
\text { computed in subroutine HEATCG. }\end{array}$ \\
\hline HFGR & - & $\begin{array}{l}\text { Heat flux across the right boundary of } \\
\text { cell } i, j, k \text { for the gas due to conduction, } \\
\text { computed in subroutine HEATCG. }\end{array}$ \\
\hline HFGT & - & $\begin{array}{l}\text { Heat flux across the top boundary of cell } \\
\mathrm{i}, \mathrm{j}, \mathrm{k} \text { for the gas due to conduction, } \\
\text { computed in subroutine HEATCG. }\end{array}$ \\
\hline HFLA & - & $\begin{array}{l}\text { Same as HFGA, except for the liquid, } \\
\text { computed in subroutine HEATCL. }\end{array}$ \\
\hline HFLB & - & $\begin{array}{l}\text { Same as HFGB, except for the liquid, } \\
\text { computed in subroutine HEATCL. }\end{array}$ \\
\hline HFLF & - & $\begin{array}{l}\text { Same as HFGF, except for the liquid, } \\
\text { computed in subroutine HEATCL. }\end{array}$ \\
\hline HFLL & - & $\begin{array}{l}\text { Same as HFGL, except for the liquid, } \\
\text { computed in subroutine HEATCL. }\end{array}$ \\
\hline
\end{tabular}


Table A.6: Continuation of the K-FIX(GT) variable list.

\begin{tabular}{|c|c|c|}
\hline Fortran Symbol & $\begin{array}{c}\text { Algebraic } \\
\text { Symbol }\end{array}$ & Definition \\
\hline HFLR & - & $\begin{array}{l}\text { Same as HFGR, except for the liquid, } \\
\text { computed in subroutine HEATCL. }\end{array}$ \\
\hline HFLT & - & $\begin{array}{l}\text { Same as HFGT, except for the liquid, } \\
\text { computed in subroutine HEATCL. }\end{array}$ \\
\hline $\mathrm{HH}(\mathrm{I}, \mathrm{J}, \mathrm{K})$ & - & $\begin{array}{l}\text { Enthalpy exchanged between fluids due } \\
\text { to phase changes. Computed in subrou- } \\
\text { tine MASSX. }\end{array}$ \\
\hline $\mathrm{I}$ & $i$ & $\begin{array}{l}\text { Computing mesh column index ( } \mathrm{r}- \\
\text { direction). }\end{array}$ \\
\hline IB & - & $\begin{array}{l}\text { Number of cells in the radial direction } \\
\text { excluding the two fictitious columns } \\
\text { along the left and right boundaries of } \\
\text { the computing mesh, IB = IB2 - } 2 \text {. }\end{array}$ \\
\hline IB1 & - & $\mathrm{IB} 1=\mathrm{IB} 2-1$ \\
\hline IB2 & - & Input. \\
\hline IB2XJB2 & - & $\begin{array}{l}\text { IB2XJB2 = IB2 * JB2. Used to trans- } \\
\text { late from three dimensional array in- } \\
\text { dices to one dimensional array indices. }\end{array}$ \\
\hline ICJ & - & $\begin{array}{l}\text { Used to compute cell indices. Calcu- } \\
\text { lated in subroutine INDIX. }\end{array}$ \\
\hline ICMARK & - & $\begin{array}{l}\text { Total number of lagrangian markers. } \\
\text { Calculated in subroutine LAGMARK. }\end{array}$ \\
\hline $\operatorname{ICOR}(\mathrm{L}, \mathrm{M}, \mathrm{N})$ & - & Input. \\
\hline IDRG & - & Input. \\
\hline IHEAT & - & Input. \\
\hline IJ & - & $\begin{array}{l}\text { Index of cell centered quantities for cell } \\
\mathrm{i}, \mathrm{j}, \mathrm{k} \text {. }\end{array}$ \\
\hline IJ A & - & $\begin{array}{l}\text { Index of cell centered quantities for cell } \\
i, j, k+1 \text {. }\end{array}$ \\
\hline IJAA & - & $\begin{array}{l}\text { Index of cell centered quantities for cell } \\
i, j, k+2 \text {. }\end{array}$ \\
\hline IJAL & - & $\begin{array}{l}\text { Index of cell centered quantities for cell } \\
i-1, j, k+1 \text {. }\end{array}$ \\
\hline
\end{tabular}


Table A.7: Continuation of the K-FIX(GT) variable list.

\begin{tabular}{|c|c|c|}
\hline Fortran Symbol & $\begin{array}{c}\text { Algebraic } \\
\text { Symbol }\end{array}$ & Definition \\
\hline IJAR & - & $\begin{array}{l}\text { Index of cell centered quantities for cell } \\
i+1, j, k+1 \text {. }\end{array}$ \\
\hline IJB & - & $\begin{array}{l}\text { Index of cell centered quantities associ- } \\
\text { ated with cell } i, j-1, k \text {. }\end{array}$ \\
\hline IJBA & - & $\begin{array}{l}\text { Index of cell centered quantities for cell } \\
i, j-1, k+1 \text {. }\end{array}$ \\
\hline IJBR & - & $\begin{array}{l}\text { Index of cell centered quantities associ- } \\
\text { ated with cell } i+1, j-1, k \text {. }\end{array}$ \\
\hline IJF & - & $\begin{array}{l}\text { Index of cell centered quantities for cell } \\
i, j, k-1 \text {. }\end{array}$ \\
\hline IJFR & - & $\begin{array}{l}\text { Index of cell centered quantities for cell } \\
i+1, j, k-1 \text {. }\end{array}$ \\
\hline IJL & - & $\begin{array}{l}\text { Index of cell centered quantities associ- } \\
\text { ated with cell } \mathrm{i}-1, \mathrm{j}, \mathrm{k} \text {. }\end{array}$ \\
\hline IJM & - & $\begin{array}{l}\text { Index of cell centered quantities for cell } \\
i, j-1, k \text {. }\end{array}$ \\
\hline IJP & - & $\begin{array}{l}\text { Index of cell centered quantities for cell } \\
i, j+1, k \text {. }\end{array}$ \\
\hline IJPLOT(M,N) & - & Input. \\
\hline IJR & - & $\begin{array}{l}\text { Index of cell centered quantities associ- } \\
\text { ated with cell } i+1, j, k \text {. }\end{array}$ \\
\hline IJRR & - & $\begin{array}{l}\text { Index of cell centered quantities associ- } \\
\text { ated with cell } \mathrm{i}+2, \mathrm{j}, \mathrm{k} \text {. }\end{array}$ \\
\hline IJT & - & $\begin{array}{l}\text { Index of cell centered quantities associ- } \\
\text { ated with cell } i, j+1, k \text {. }\end{array}$ \\
\hline IJTA & - & $\begin{array}{l}\text { Index of cell centered quantities for cell } \\
\mathrm{i}, \mathrm{j}+1, \mathrm{k}+1 \text {. }\end{array}$ \\
\hline IJTF & - & $\begin{array}{l}\text { Index of cell centered quantities for cell } \\
i, j+1, k-1 \text {. }\end{array}$ \\
\hline IJTL & - & $\begin{array}{l}\text { Index of cell centered quantities associ- } \\
\text { ated with cell } \mathrm{i}-1, \mathrm{j}+1, \mathrm{k} \text {. }\end{array}$ \\
\hline
\end{tabular}


Table A.8: Continuation of the K-FIX(GT) variable list.

\begin{tabular}{|c|c|c|}
\hline Fortran Symbol & $\begin{array}{l}\text { Algebraic } \\
\text { Symbol }\end{array}$ & Definition \\
\hline IJTR & - & $\begin{array}{l}\text { Index of cell centered quantities associ- } \\
\text { ated with cell } i+1, j+1, k \text {. }\end{array}$ \\
\hline IJTT & - & $\begin{array}{l}\text { Index of cell centered quantities associ- } \\
\text { ated with cell } i, j+2, k \text {. }\end{array}$ \\
\hline IKM & - & $\begin{array}{l}\text { Index of cell centered quantities for cell } \\
i, j, k-1 \text {. }\end{array}$ \\
\hline IKP & - & $\begin{array}{l}\text { Index of cell centered quantities for cell } \\
\mathrm{i}, \mathrm{j}, \mathrm{k}+1 \text {. }\end{array}$ \\
\hline $\operatorname{IKPLOT}(\mathrm{M}, \mathrm{N})$ & - & Input. \\
\hline IL & - & $\mathrm{IL}=\mathrm{IB} 1$ \\
\hline IMASS & - & Input. \\
\hline IMJ & - & Index of cell $\mathrm{i}-1, \mathrm{j}, \mathrm{k}$ \\
\hline IMJM & - & $\begin{array}{l}\text { NO LONGER IN USE. Index of cell } \mathrm{i}-1 \text {, } \\
\mathrm{j}-1, \mathrm{k} \text {. }\end{array}$ \\
\hline IMJP & - & Index of cell $\mathrm{i}-1, \mathrm{j}+1, \mathrm{k}$ \\
\hline IMKP & - & $\begin{array}{l}\text { Index of cell centered quantities for cell } \\
i-1, j, k+1 \text {. }\end{array}$ \\
\hline IMPAD & - & Input. \\
\hline IMPMS & - & Input. \\
\hline INCJ & - & Indexing variable, computed in START. \\
\hline INCK & - & Indexing variable, computed in START. \\
\hline IP1 & - & Input. \\
\hline IP2 & - & Input. \\
\hline IPJ & - & Index of cell $\mathrm{i}+1, \mathrm{j}, \mathrm{k}$. \\
\hline IPJM & - & Index of cell $\mathrm{i}+1, \mathrm{j}-1, \mathrm{k}$. \\
\hline IPJP & - & Index of cell $i+1, j+1, k$ \\
\hline IPKM & - & $\begin{array}{l}\text { Index of cell centered quantities for cell } \\
\mathrm{i}+1, \mathrm{j}, \mathrm{k}-1 \text {. }\end{array}$ \\
\hline IPKP & - & $\begin{array}{l}\text { Index of cell centered quantities for cell } \\
\mathrm{i}+1, j, k+1 \text {. }\end{array}$ \\
\hline
\end{tabular}


Table A.9: Continuation of the K-FIX(GT) variable list.

\begin{tabular}{|c|c|c|}
\hline Fortran Symbol & $\begin{array}{l}\text { Algebraic } \\
\text { Symbol }\end{array}$ & Definition \\
\hline IRESET & - & Input. \\
\hline IS & - & $\mathrm{IS}=2$. \\
\hline ITC & - & Input. \\
\hline ITD & - & Input. \\
\hline $\operatorname{ITYP}(\mathrm{M})$ & - & Input. \\
\hline IVFLAG(M) & - & Input. \\
\hline IVISC & - & Input. \\
\hline IYLD & - & Input. \\
\hline $\mathbf{J}$ & $j$ & $\begin{array}{l}\text { Computing mesh row index ( } \mathrm{z}- \\
\text { direction }) \text {. }\end{array}$ \\
\hline JB & - & $\begin{array}{l}\text { Number of cells in the axial direction } \\
\text { excluding the two fictitious rows at the } \\
\text { top and bottom boundaries of the com- } \\
\text { puting mesh, JB = JB2 - } 2 \text {. }\end{array}$ \\
\hline JB1 & - & $\mathrm{JB} 1=\mathrm{JB} 2-1$ \\
\hline JB2 & - & Input. \\
\hline $\mathrm{JL}$ & - & $\mathrm{JL}=\mathrm{JB} 1$ \\
\hline JMKM & - & $\begin{array}{l}\text { Index of cell centered quantities for cell } \\
i, j-1, k-1 \text {. }\end{array}$ \\
\hline JMKP & - & $\begin{array}{l}\text { Index of cell centered quantities for cell } \\
i, j-1, k+1 \text {. }\end{array}$ \\
\hline JNM & - & $\begin{array}{l}\text { NO LONGER IN USE. Replaced by } \\
\text { NAME. Job name, input. }\end{array}$ \\
\hline JP1 & - & Input. \\
\hline JP2 & - & Input. \\
\hline JPKM & - & $\begin{array}{l}\text { Index of cell centered quantities for cell } \\
i, j+1, k-1 \text {. }\end{array}$ \\
\hline JPKP & - & $\begin{array}{l}\text { Index of cell centered quantities for cell } \\
i, j+1, k+1 \text {. }\end{array}$ \\
\hline
\end{tabular}


Table A.10: Continuation of the K-FIX(GT) variable list.

\begin{tabular}{|c|c|c|}
\hline Fortran Symbol & $\begin{array}{l}\text { Algebraic } \\
\text { Symbol }\end{array}$ & Definition \\
\hline JPLOT(K) & - & $\begin{array}{l}\text { NO LONGER IN USE. Replaced by IJ- } \\
\text { PLOT, IKPLOT, and JKPLOT. Input. }\end{array}$ \\
\hline JS & - & $\mathrm{JS}=2$ \\
\hline $\mathrm{K}$ & $k$ & Computing mesh index ( $\phi$-direction). \\
\hline $\mathrm{KAPG}(\mathrm{I}, \mathrm{J}, \mathrm{K})$ & $\kappa_{g}$ & $\begin{array}{l}\text { Thermal conductivity for the gas, for } \\
\text { cell } i, j, k \text { ( real number). }\end{array}$ \\
\hline $\mathrm{KAPL}(\mathrm{I}, \mathrm{J}, \mathrm{K})$ & $\kappa l$ & $\begin{array}{l}\text { Thermal conductivity for the liquid, for } \\
\text { cell } i, j, k \text { ( real number). }\end{array}$ \\
\hline KB & - & $\begin{array}{l}\text { Number of cells in the azimuthal direc- } \\
\text { tion excluding the two fictitious rows at } \\
\text { the aft and fore boundaries of the com- } \\
\text { puting mesh, KB }=\mathrm{KB} 2-2 \text {. }\end{array}$ \\
\hline KB1 & - & $\mathrm{KB} 1=\mathrm{KB} 2-1$ \\
\hline KB2 & - & Input. \\
\hline KDRAG(I,J,K) & $K$ & $\begin{array}{l}\text { Interfacial friction function for cell } \mathrm{i}, \mathrm{j} \text {, } \\
\mathrm{k} \text { ( real number). Computed in subrou- } \\
\text { tine KDRAGS. }\end{array}$ \\
\hline $\mathrm{KJPLOT}(\mathrm{M}, \mathrm{N})$ & - & Input. \\
\hline $\mathrm{KL}$ & - & $\mathrm{KL}=\mathrm{KB1}$ \\
\hline KP1 & - & Input. \\
\hline KP2 & - & Input. \\
\hline KS & - & $\mathrm{KS}=2$ \\
\hline $\mathrm{LFL}(\mathrm{I}, \mathrm{J}, \mathrm{K})$ & - & Indexing variables. \\
\hline $\operatorname{LHEAT}(\mathrm{I}, \mathrm{J}, \mathrm{K})$ & $L$ & $\begin{array}{l}\text { NO LONGER IN USE. Calculated } \\
\text { when needed. Latent heat of vaporiza- } \\
\text { tion for cell } i, j, k \text {. Computed in sub- } \\
\text { routine SAT. }\end{array}$ \\
\hline LPR & - & Input. \\
\hline $\operatorname{MARK}(\mathrm{M}, \mathrm{N})$ & - & Input. \\
\hline
\end{tabular}


Table A.11: Continuation of the K-FIX(GT) variable list.

\begin{tabular}{|c|c|c|}
\hline Fortran Symbol & $\begin{array}{c}\text { Algebraic } \\
\text { Symbol }\end{array}$ & Definition \\
\hline$\overline{\mathrm{MAXM}}$ & - & Indexing variable. \\
\hline $\operatorname{MFL}(\mathrm{M}, \mathrm{N})$ & - & Indexing variables. \\
\hline $\operatorname{MFLAG}(\mathrm{I}, \mathrm{J}, \mathrm{K})$ & - & Indexing variables. \\
\hline MRKZNS & - & Input. \\
\hline MUG(I,J,K) & $\mu_{g}$ & $\begin{array}{l}\text { Shear viscosity of the gas for cell } i, j, k \\
\text { ( real number). Computed in subrou- } \\
\text { tine VISC. }\end{array}$ \\
\hline MUL(I,J,K) & $\mu_{i}$ & $\begin{array}{l}\text { Shear viscosity of the liquid for cell } i, j \text {, } \\
k \text { ( real number). Computed in subrou- } \\
\text { tine VISC. }\end{array}$ \\
\hline NAME & - & Input. \\
\hline NCYCLE & - & NOT IN USE. \\
\hline NCYDMP & - & $\begin{array}{l}\text { NOT IN USE. Replace by automatic } \\
\text { writes to tape } 15 \text { every cycle. The num- } \\
\text { ber of cycles between writes (dumps) on } \\
\text { TAPE5, as specified by the input vari- } \\
\text { able NSDMP. Set in program KFIX as } \\
\text { NCYDMP = NSDMP. }\end{array}$ \\
\hline NFILE & - & Input. \\
\hline NIT & - & $\begin{array}{l}\text { Iteration counter used in subroutine } \\
\text { ITER. }\end{array}$ \\
\hline NMRKX & - & Input. \\
\hline NMRKY & - & Input. \\
\hline NMRKZ & - & Input. \\
\hline NO & - & Input. \\
\hline NOI & - & Input. \\
\hline NPNT(M) & - & Input. \\
\hline NPSET & - & Input. \\
\hline NSDMP & - & Input. \\
\hline $\operatorname{NSL}(\mathrm{M})$ & - & Input. \\
\hline $\mathrm{NSO}(\mathrm{M})$ & - & Input. \\
\hline
\end{tabular}


Table A.12: Continuation of the K-FIX(GT) variable list.

\begin{tabular}{|c|c|c|}
\hline Fortran Symbol & $\begin{array}{c}\text { Algebraic } \\
\text { Symbol }\end{array}$ & Definition \\
\hline NTD & - & Input. \\
\hline NWDMP & - & Input. \\
\hline NX1 & - & $\begin{array}{l}\text { Parameter, must be equal to IB2. Used } \\
\text { to dimension many arrays. }\end{array}$ \\
\hline NX2 & - & $\begin{array}{l}\text { Parameter, must be equal to JB2. Used } \\
\text { to dimension many arrays. }\end{array}$ \\
\hline NX3 & - & $\begin{array}{l}\text { Parameter, must be equal to KB2. Used } \\
\text { to dimension many arrays. }\end{array}$ \\
\hline $\mathrm{NZ1}$ & - & $\begin{array}{l}\text { Parameter, used to dimension the } \mathrm{C} \\
\text { array. }\end{array}$ \\
\hline NZ2 & - & $\begin{array}{l}\text { Parameter, used to dimension the FLO } \\
\text { and FLOA arrays. }\end{array}$ \\
\hline NZ3 & - & $\begin{array}{l}\text { Parameter, the number of different } \\
\text { types of } 2 \mathrm{D} \text { plots. Used as the first } \\
\text { dimension of IJPLOT, IKPLOT, and } \\
\text { KJPLOT. }\end{array}$ \\
\hline $\mathrm{N} 24$ & - & $\begin{array}{l}\text { Parameter, the number of different } \\
\text { heights for the same type of } 2 \mathrm{D} \text { plot. } \\
\text { Used as the second dimension of IJ- } \\
\text { PLOT, IKPLOT, and KJPLOT. }\end{array}$ \\
\hline NZ5 & - & $\begin{array}{l}\text { Parameter, used as the first dimension } \\
\text { of the MFL array. }\end{array}$ \\
\hline NZ6 & - & $\begin{array}{l}\text { F'arameter, used as the second dimen- } \\
\text { sion of the MFL array. }\end{array}$ \\
\hline NZ7 & - & Parameter, not used anymore. \\
\hline NZ8 & - & $\begin{array}{l}\text { Parameter, used to dimension the NSL } \\
\text { array. }\end{array}$ \\
\hline NZ9 & - & $\begin{array}{l}\text { Parametes, sed to dimension the NSO } \\
\text { array. }\end{array}$ \\
\hline NZ10 & - & $\begin{array}{l}\text { Parameter, set to six, allows upper and } \\
\text { lower bounds on the three axes. Used as } \\
\text { the first dimensions of OB and OVERB. }\end{array}$ \\
\hline
\end{tabular}


Table A.13: Continuation of the K-FIX(GT) variable list.

\begin{tabular}{|c|c|c|}
\hline Fortran Symbol & $\begin{array}{l}\text { Algebraic } \\
\text { Symbol }\end{array}$ & Definition \\
\hline NZ11 & - & $\begin{array}{l}\text { Parameter, set to the maximum num- } \\
\text { ber of obstacles and overlay regions al- } \\
\text { lowed. Used as the second dimension of } \\
\text { OB and OVERB, and the only dimen- } \\
\text { sion of IVFLAG and the OV* variables. }\end{array}$ \\
\hline NZ12 & - & $\begin{array}{l}\text { Parameter, used to dimension the } \\
\text { SCALE variable. }\end{array}$ \\
\hline $\mathrm{OB}(\mathrm{M}, \mathrm{N})$ & - & Input. \\
\hline OMTFA & - & $\begin{array}{l}\text { Flux of }(1-\theta) \text { across the aft boundary } \\
\text { of cell } i, j, k \text {. Computed in subroutine } \\
\text { THF. }\end{array}$ \\
\hline OMTFB(I) & - & $\begin{array}{l}\text { Flux of }(1-\theta) \text { across the bottom bound- } \\
\text { ary of cell } i, j, k \text {. Computed in subrou- } \\
\text { tine THF. }\end{array}$ \\
\hline $\operatorname{OMTFF}(\mathrm{I}, \mathrm{J})$ & - & $\begin{array}{l}\text { Flux of }(1-\theta) \text { across the fore boundary } \\
\text { of cell } i, j, k \text {. Computed in subroutine } \\
\text { THF. }\end{array}$ \\
\hline OMTFL & - & $\begin{array}{l}\text { Flux of }(1-\theta) \text { across the left boundary } \\
\text { of cell } i, j, k \text {. Computed in subroutine } \\
\text { THF. }\end{array}$ \\
\hline OMTFR & - & $\begin{array}{l}\text { Flux of }(1-\theta) \text { across the right boundary } \\
\text { of cell } i, j, k \text {. Computed in subroutine } \\
\text { THF. }\end{array}$ \\
\hline OMTFT & - & $\begin{array}{l}\text { Flux of }(1-\theta) \text { across the top boundary } \\
\text { of cell } i, j, k \text {. Computed in subroutine } \\
\text { THF. }\end{array}$ \\
\hline OVERB(M,N) & - & Input. \\
\hline $\mathrm{OVPO}(\mathrm{M})$ & - & Input. \\
\hline OVTGO(M) & - & Input. \\
\hline OVTHO(M) & - & Input. \\
\hline OVTLO(M) & - & Input. \\
\hline OVUOG(M) & - & Input. \\
\hline OVUOL(M) & - & Input. \\
\hline OVVOG(M) & - & Input. \\
\hline
\end{tabular}


Table A.14: Continuation of the K-FIX(GT) variable list.

\begin{tabular}{|c|c|c|}
\hline Fortran Symbol & $\begin{array}{l}\text { Algebraic } \\
\text { Symbol }\end{array}$ & Definition \\
\hline OVVOL(M) & - & Input. \\
\hline OVWOG(M) & - & Input. \\
\hline OVWOL $(\mathrm{M})$ & - & Input. \\
\hline OVXAIRO(M) & - & Input. \\
\hline OVXDEBO(M) & - & Input. \\
\hline $\mathrm{P}(\mathrm{I}, \mathrm{J}, \mathrm{K})$ & $P$ & Pressure in cell $\mathrm{i}, \mathrm{j}, \mathrm{k}$ \\
\hline $\mathrm{P} 1$ & - & $\begin{array}{l}\text { Pressure associated with } D_{g}\left(D_{l}\right)=D 1 \text {. } \\
\text { Used in subroutine NEWP. }\end{array}$ \\
\hline P2 & - & $\begin{array}{l}\text { Pressure associated with } D_{g}\left(D_{l}\right)=D 2 \text {. } \\
\text { Used in subroutine NEWP. }\end{array}$ \\
\hline P3 & - & $\begin{array}{l}\text { Pressure associated with } D_{g}\left(D_{l}\right)=D 3 \text {. } \\
\text { Used in subroutine NEWP. }\end{array}$ \\
\hline PINB & - & Input. \\
\hline PINL & - & Input. \\
\hline PINR & - & Input. \\
\hline PINT & - & Input. \\
\hline $\mathrm{PO}$ & - & Input. \\
\hline $\mathrm{R}(\mathrm{I})$ & $r_{i}$ & $\begin{array}{l}\text { Radial coordinate of the center of cell } i \text {, } \\
j, k \text {. }\end{array}$ \\
\hline RAGS & $\left(a_{g}\right)^{-2}$ & $\begin{array}{l}\text { Square of the reciprocal gas adiabatic } \\
\text { sound speed. }\end{array}$ \\
\hline RALS & $\left(a_{l}\right)^{-2}$ & $\begin{array}{l}\text { Square of the reciprocal liquid adiabatic } \\
\text { sound speed. }\end{array}$ \\
\hline $\mathrm{RB}(\mathrm{I})$ & $r_{i+1 / 2}$ & $\begin{array}{l}\text { Radial coordinate of the right boundary } \\
\text { of cell } i, j, k \text {. }\end{array}$ \\
\hline RDA & $\delta \phi^{-1}$ & $\begin{array}{l}\text { Reciprocal of the cell's azimuthal } \\
\text { dimension. }\end{array}$ \\
\hline RDA2 & $\delta \phi^{-2}$ & $\begin{array}{l}\text { Reciprocal of the cell's azimuthal di- } \\
\text { mension squared. }\end{array}$ \\
\hline $\mathrm{RDPH}$ & $\delta \phi^{-1}$ & $\begin{array}{l}\text { Reciprocal of the cell's azimuthal } \\
\text { dimension. }\end{array}$ \\
\hline RDR & $\delta r^{-1}$ & Reciprocal of the cell's radial dimension. \\
\hline
\end{tabular}


Table A.15: Continuation of the K-FIX(GT) variable list.

\begin{tabular}{|c|c|c|}
\hline Fortran Symbol & $\begin{array}{l}\text { Algebraic } \\
\text { Symbol }\end{array}$ & Definition \\
\hline RDR2 & $\delta r^{-2}$ & $\begin{array}{l}\text { Reciprocal of the cell's radial dimension } \\
\text { squared. }\end{array}$ \\
\hline $\mathrm{RDZ}$ & $\delta z^{-1}$ & Reciprocal of the cell's axial dimension. \\
\hline RDZ2 & $\delta z^{-2}$ & $\begin{array}{l}\text { Reciprocal of the cell's axial dimension } \\
\text { squared. }\end{array}$ \\
\hline RGFA(I,J,K) & - & $\begin{array}{l}\text { Flux of } \rho_{g}^{\prime} \text { across the aft boundary of } \\
\text { cell } i, j, k \text {. }\end{array}$ \\
\hline $\operatorname{RGFR}(\mathrm{I}, \mathrm{J}, \mathrm{K})$ & - & $\begin{array}{l}\text { Flux of } \rho_{g}^{\prime} \text { across the right boundary of } \\
\text { cell } i, j, k \text {. }\end{array}$ \\
\hline RGFT(I,J,K) & - & $\begin{array}{l}\text { Flux of } \rho_{g}^{\prime} \text { across the top boundary of } \\
\text { cell } \mathrm{i}, \mathrm{j}, \mathrm{k} \text {. }\end{array}$ \\
\hline $\mathrm{RGP}(\mathrm{I}, \mathrm{J}, \mathrm{K})$ & $\rho_{g}^{\prime}$ & $\begin{array}{l}\text { Macroscopic density of the gas for cell } i \text {, } \\
j, k \text {. }\end{array}$ \\
\hline RGPN(I,J,K) & $\left(\rho_{g}^{\prime}\right)^{n}$ & $\begin{array}{l}\text { Macroscopic density of the gas for cell } i \text {, } \\
j, k \text { at time level } n \text {. }\end{array}$ \\
\hline RHEAT(I,J,K) & $R$ & $\begin{array}{l}\text { Interfacial heat transfer function for cell } \\
i, j, k \text {. }\end{array}$ \\
\hline $\mathrm{RL}(\mathrm{I}, \mathrm{J}, \mathrm{K})$ & $\rho_{l}$ & $\begin{array}{l}\text { Microscopic density of the liquid for cell } \\
i, j, k \text {. }\end{array}$ \\
\hline $\operatorname{RLFA}(\mathrm{I}, \mathrm{J}, \mathrm{K})$ & - & $\begin{array}{l}\text { Flux of } \rho_{l}^{\prime} \text { across the aft boundary of cell } \\
i, j, k \text {. }\end{array}$ \\
\hline $\operatorname{RLFR}(\mathrm{I}, \mathrm{J}, \mathrm{K})$ & - & $\begin{array}{l}\text { Flux of } \rho_{l}^{\prime} \text { across the right boundary of } \\
\text { cell } i, j, k \text {. }\end{array}$ \\
\hline RLFT(I,J,K) & - & $\begin{array}{l}\text { Flux of } \rho_{l}^{\prime} \text { across the top boundary of } \\
\text { cell } \mathrm{i}, \mathrm{j}, \mathrm{k} \text {. }\end{array}$ \\
\hline $\operatorname{RLP}(\mathrm{I}, \mathrm{J}, \mathrm{K})$ & $\rho_{l}^{\prime}$ & $\begin{array}{l}\text { Macroscopic density of the liquid for cell } \\
i, j, k \text {. }\end{array}$ \\
\hline RLPN(I,J,K) & $\left(\rho_{l}^{\prime}\right)^{n}$ & $\begin{array}{l}\text { Macroscopic density of the liquid for cell } \\
i, j, k \text { at time level } n \text {. }\end{array}$ \\
\hline RODEB & $\rho_{\text {deb }}$ & Input. \\
\hline $\mathrm{ROG}(\mathrm{I}, \mathrm{J}, \mathrm{K})$ & $\rho_{g}$ & $\begin{array}{l}\text { Microscopic density of the gas for cell i, } \\
j, k \text {. }\end{array}$ \\
\hline
\end{tabular}


Table A.16: Continuation of the K-FIX(GT) variable list.

\begin{tabular}{|c|c|c|}
\hline Fortran Symbol & $\begin{array}{l}\text { Algebraic } \\
\text { Symbol }\end{array}$ & Definition \\
\hline$\overline{\mathrm{RRB}}(\mathrm{I})$ & $\left(r_{i+1 / 2}\right)^{-1}$ & $\begin{array}{l}\text { Reciprocal of the radial coordinate of } \\
\text { the right boundary of cell } i, j, k \text {. }\end{array}$ \\
\hline RRIDR(I) & $\left(r_{i} \delta r\right)^{-1}$ & $\begin{array}{l}\text { Reciprocal of the product of the cell } \\
\text { center radius and the cell's radial } \\
\text { dimension. }\end{array}$ \\
\hline RUG(I,J,K) & $\left(\bar{\rho}_{g}^{\prime} u_{g}\right)_{i+1 / 2, j, k}$ & $\begin{array}{l}\text { Radial component of the gas momen- } \\
\text { tum density that accounts for the effects } \\
\text { of convection and viscous stress. }\end{array}$ \\
\hline $\mathrm{RUL}(\mathrm{I}, \mathrm{J}, \mathrm{K})$ & $\left(\overline{\rho_{l}^{\prime} u_{l}}\right)_{i+1 / 2, j, k}$ & $\begin{array}{l}\text { Radial component of the liquid momen- } \\
\text { tum density that accounts for the effects } \\
\text { of convection and viscous stress. }\end{array}$ \\
\hline $\mathrm{RVG}(\mathrm{I}, \mathrm{J}, \mathrm{K})$ & $\left(\bar{\rho}_{g}^{\prime} v_{g}\right)_{i, j+1 / 2, k}$ & $\begin{array}{l}\text { Axial component of the gas momentum } \\
\text { density that accounts for the effects of } \\
\text { convection, gravity, and viscous stress. }\end{array}$ \\
\hline $\mathrm{RVL}(\mathrm{I}, \mathrm{J}, \mathrm{K})$ & $\left(\widetilde{\rho_{l}^{\prime} v_{l}}\right)_{i, j+1 / 2, k}$ & $\begin{array}{l}\text { Axial component of the liquid momen- } \\
\text { tum density that accounts for the ef- } \\
\text { fects of convection, gravity, and viscous } \\
\text { stress. }\end{array}$ \\
\hline $\mathrm{RWG}(\mathrm{I}, \mathrm{J}, \mathrm{K})$ & $\left(\rho_{g}^{T} w_{g}\right)_{i, j, k+1 / 2}$ & $\begin{array}{l}\text { Azimuthal component of the gas mo- } \\
\text { mentum density that accounts for the } \\
\text { effects of convection and viscous stress. }\end{array}$ \\
\hline $\mathrm{RWL}(\mathrm{I}, \mathrm{J}, \mathrm{K})$ & $\left(\widetilde{\rho_{l}^{\prime} v_{l}}\right)_{i, j+1 / 2, k}$ & $\begin{array}{l}\text { Azimuthal component of the liquid mo- } \\
\text { mentum density that accounts for the } \\
\text { effects of convection and viscous stress. } \\
\text { Input. }\end{array}$ \\
\hline SECREQ & - & $\begin{array}{l}\text { NOT IN USE. No more internal checks } \\
\text { on job time limits. Computer time } \\
\text { requested for the problem in seconds. } \\
\text { Computed in program KFIX from JOB } \\
\text { card data. }\end{array}$ \\
\hline SIEG(I,J,K) & $I_{g}$ & $\begin{array}{l}\text { Specific internal energy of the gas for } \\
\text { cell } i, j, k \text {. }\end{array}$ \\
\hline $\operatorname{SIEGN}(\mathrm{I}, \mathrm{J}, \mathrm{K})$ & $\left(I_{g}\right)^{n}$ & $\begin{array}{l}\text { Specific internal energy of the gas for } \\
\text { cell } i, j, k \text { at time level } n \text {. }\end{array}$ \\
\hline
\end{tabular}


Table A.17: Continuation of the K-FIX(GT) variable list.

\begin{tabular}{|c|c|c|}
\hline Fortran Symbol & $\begin{array}{c}\text { Algebraic } \\
\text { Symbol }\end{array}$ & Definition \\
\hline SIEL(I,J,K) & $I_{l}$ & $\begin{array}{l}\text { Specific internal energy of the liquid for } \\
\text { cell } i, j, k \text {. }\end{array}$ \\
\hline $\operatorname{SIELN}(\mathrm{I}, \mathrm{J}, \mathrm{K})$ & $\left(I_{1}\right)^{n}$ & $\begin{array}{l}\text { Specific internal energy of the liquid for } \\
\text { cell } i, j, k \text { at time level } n \text {. }\end{array}$ \\
\hline SIGPP & $\sigma_{g \phi \phi}$ & $\begin{array}{l}\text { NO LONGER IN USE. Calculated } \\
\text { when needed. Azimuthal stress used to } \\
\text { compute viscous work in the gas inter- } \\
\text { nal energy equation. }\end{array}$ \\
\hline SIGRR & $\sigma_{g r r}$ & $\begin{array}{l}\text { NO LONGER IN USE. Calculated } \\
\text { when needed. Radial stress used to } \\
\text { compute viscous work in the gas inter- } \\
\text { nal energy equation. }\end{array}$ \\
\hline SIGRZ & $\sigma_{g r z}$ & $\begin{array}{l}\text { NO LONGER IN USE. Calculated } \\
\text { when needed. Shear stress used to com- } \\
\text { pute viscous work in the gas internal en- } \\
\text { ergy equation. }\end{array}$ \\
\hline SIGZZ & $\sigma_{g z z}$ & $\begin{array}{l}\text { NO LONGER IN USE. Calculated } \\
\text { when needed. Axial stress used to com- } \\
\text { pute viscous work in the gas internal en- } \\
\text { ergy equation. }\end{array}$ \\
\hline SILPP & $\sigma_{l \phi \phi}$ & $\begin{array}{l}\text { NO LONGER IN USE. Calculated } \\
\text { when needed. Azimuthal stress used to } \\
\text { compute viscous work in the liquid in- } \\
\text { ternal energy equation. }\end{array}$ \\
\hline SILRR & $\sigma_{l r r}$ & $\begin{array}{l}\text { NO LONGER IN USE. Calculated } \\
\text { when needed. Radial stress used to } \\
\text { compute viscous work in the liquid in- } \\
\text { ternal energy equation. }\end{array}$ \\
\hline SILRZ & $\sigma_{l r z}$ & $\begin{array}{l}\text { NO LONGER IN USE. Calculated } \\
\text { when needed. Shear stress used to com- } \\
\text { pute viscous work in the liquid internal } \\
\text { energy equation. }\end{array}$ \\
\hline
\end{tabular}


Table A.18: Continuation of the K-FIX(GT) variable list.

\begin{tabular}{|c|c|c|}
\hline Fortran Symbol & $\begin{array}{c}\text { Algebraic } \\
\text { Symbol }\end{array}$ & Definition \\
\hline SILZZ & $\sigma_{l z z}$ & $\begin{array}{l}\text { NO LONGER IN USE. Calculated } \\
\text { when needed. Axial stress used to com- } \\
\text { pute viscous work in the liquid internal } \\
\text { energy equation. }\end{array}$ \\
\hline SUGB & $\left(\theta \sigma_{g z r}\right)_{i+1 / 2, j-1 / 2, k}$ & $\begin{array}{l}\text { NO LONGER IN USE. Calculated } \\
\text { when needed. Product of void fraction } \\
\text { and shear stress used to compute gas } \\
\text { radial momentum. }\end{array}$ \\
\hline SUGC & $\left(\theta \sigma_{g \phi \phi}\right)_{i+1 / 2, j, k}$ & $\begin{array}{l}\text { NO LONGER IN USE. Calculated } \\
\text { when needed. Product of void fraction } \\
\text { and azimuthal stress used to compute } \\
\text { gas radial momentum. }\end{array}$ \\
\hline SUGL & $\left(r \theta \sigma_{g r r}\right)_{i, j, k}$ & $\begin{array}{l}\text { NO LONGER IN USE. Calculated } \\
\text { when needed. Product of radius, void } \\
\text { fraction, and radial stress used to com- } \\
\text { pute gas radial momentum. }\end{array}$ \\
\hline SUGR & $\left(r \theta \sigma_{g r r}\right)_{i+1, j, k}$ & $\begin{array}{l}\text { NO LONGER IN USE. Calculated } \\
\text { when needed. Same as SUGL, but eval- } \\
\text { uated at mesh location } i+1, j, k \text {. }\end{array}$ \\
\hline SUGT & $\left(\theta \sigma_{g r z}\right)_{i+1 / 2, j+1 / 2, k}$ & $\begin{array}{l}\text { NO LONGER IN USE. Calculated } \\
\text { when needed. Same as SUGB, but eval- } \\
\text { uated at mesh location } i+1 / 2, j+1 / 2, k \text {. }\end{array}$ \\
\hline SULB & {$\left[(1-\theta) \sigma_{l r z}\right]_{i+1 / 2, j-1 / 2, k}$} & $\begin{array}{l}\text { NO LONGER IN USE. Calculated } \\
\text { when needed. Same as SUGB, except } \\
\text { for the liquid. }\end{array}$ \\
\hline SULC & {$\left[(1-\theta) \sigma_{l \phi \phi}\right]_{i+1 / 2, j, k}$} & $\begin{array}{l}\text { NO LONGER IN USE. Calculated } \\
\text { when needed. Same as SUGC, except } \\
\text { for the liquid. }\end{array}$ \\
\hline SULL & {$\left[r(1-\theta) \sigma_{l r r}\right]_{i, j, k}$} & $\begin{array}{l}\text { NO LONGER IN USE. Calculated } \\
\text { when needed. Same as SUGL, except } \\
\text { for the liquid. }\end{array}$ \\
\hline
\end{tabular}


Table A.19: Continuation of the K-FIX(GT) variable list.

\begin{tabular}{|c|c|c|}
\hline Fortran Symbol & $\begin{array}{c}\text { Algebraic } \\
\text { Symbol }\end{array}$ & Definition \\
\hline SULR & {$\left[r(1-\theta) \sigma_{l r r}\right]_{i+1, j, k}$} & $\begin{array}{l}\text { NO LONGER IN USE. Calculated } \\
\text { when needed. Same as SUGR, except } \\
\text { for the liquid. }\end{array}$ \\
\hline SULT & {$\left[(1-\theta) \sigma_{l r z}\right]_{i+1 / 2, j+1 / 2, k}$} & $\begin{array}{l}\text { NO LONGER IN USE. Calculated } \\
\text { when needed. Same as SUGT, except } \\
\text { for the liquid. }\end{array}$ \\
\hline SURWA & - & $\begin{array}{l}\text { Work done on the surroundings of the } \\
\text { explosion zone. The area for gas flow } \\
\text { is taken to be the product of the av- } \\
\text { erage void fraction and the interfacial } \\
\text { area. Computed in subroutine WORK. }\end{array}$ \\
\hline SURWD & - & $\begin{array}{l}\text { Work done on the surroundings of the } \\
\text { explosion zone. The area for gas flow is } \\
\text { taken to be the product of the donor cell } \\
\text { void fraction and the interfacial area. } \\
\text { Computed in subroutine WORK. }\end{array}$ \\
\hline SVGB & $\left(\theta \sigma_{g z z}\right)_{i, j, k}$ & $\begin{array}{l}\text { NO LONGER IN USE. Calculated } \\
\text { when needed. Product void fraction and } \\
\text { axial stress used to compute gas axial } \\
\text { momentum. }\end{array}$ \\
\hline SVGL & $\left(r \theta \sigma_{g r z}\right)_{i-1 / 2, j+1 / 2, k}$ & $\begin{array}{l}\text { NO LONGER IN USE. Calculated } \\
\text { when needed. Product radius, void frac- } \\
\text { tion, and shear stress used to compute } \\
\text { gas axial momentum. }\end{array}$ \\
\hline SVGR & $\left(r \theta \sigma_{g r z}\right)_{i+1 / 2, j+1 / 2, k}$ & $\begin{array}{l}\text { NO LONGER IN USE. Calculated } \\
\text { when needed. Same as SVGL, but eval- } \\
\text { uated at mesh location } i+1 / 2, j+1 / 2, k \text {. }\end{array}$ \\
\hline SVGT & $\left(\theta \sigma_{g z z}\right)_{i, j+1, k}$ & $\begin{array}{l}\text { NO LONGER IN USE. Calculated } \\
\text { when needed. Same as SVGB, but eval- } \\
\text { uated at mesh location } i, j+1, k \text {. }\end{array}$ \\
\hline SVLB & {$\left[(1-\theta) \sigma_{l z z}\right]_{i, j, k}$} & $\begin{array}{l}\text { NO LONGER IN USE. Calculated } \\
\text { when needed. Same as SVGB, except } \\
\text { for the liquid. }\end{array}$ \\
\hline
\end{tabular}


Table A.20: Continuation of the K-FIX(GT) variable list.

\begin{tabular}{|c|c|c|}
\hline Fortran Symbol & $\begin{array}{l}\text { Algebraic } \\
\text { Symbol }\end{array}$ & Definition \\
\hline SVLL & {$\left[r(1-\theta) \sigma_{l r z}\right]_{i-1 / 2, j+1 / 2, k}$} & $\begin{array}{l}\text { NO LONGER IN USE. Calculated } \\
\text { when needed. Same as SVGL, except } \\
\text { for the liquid. }\end{array}$ \\
\hline SVLR & {$\left[r(1-\theta) \sigma_{l r z}\right]_{i+1 / 2, j+1 / 2, k}$} & $\begin{array}{l}\text { NO LONGER IN USE. Calculated } \\
\text { when needed. Same as SVGR, except } \\
\text { for the liquid. }\end{array}$ \\
\hline SVLT & {$\left[(1-\theta) \sigma_{l=z}\right]_{i, j+1, k}$} & $\begin{array}{l}\text { NO LONGER IN USE. Calculated } \\
\text { when needed. Same as SVGT, except } \\
\text { for the liquid. }\end{array}$ \\
\hline TARGET & - & $\begin{array}{l}\text { Used in the pressure iteration to provide } \\
\text { over or under relaxation. }\end{array}$ \\
\hline TBEG & - & Time at beginning of program execution \\
\hline TEMPINB & - & Input. \\
\hline TEMPINL & - & Input. \\
\hline TEMPINR & - & Input. \\
\hline TEMPINT & - & Input. \\
\hline TEMPO & - & Input. \\
\hline $\mathrm{TG}(\mathrm{I}, \mathrm{J}, \mathrm{K})$ & $T_{g}$ & Gas temperature for cell $i, j, k$. \\
\hline $\mathrm{TH}(\mathrm{I}, \mathrm{J}, \mathrm{K})$ & $\theta$ & Void fraction for cell $\mathrm{i}, \mathrm{j}, \mathrm{k}$ \\
\hline THFA & - & $\theta$ flux across aft boundary of cell $\mathrm{i}, \mathrm{j}, \mathrm{k}$. \\
\hline THFB(I) & - & $\begin{array}{l}\theta \text { flux across bottom boundary of cell } \mathrm{i} \text {, } \\
\mathrm{j}, \mathrm{k} \text {. }\end{array}$ \\
\hline $\operatorname{THFF}(\mathrm{I}, \mathrm{J})$ & - & $\begin{array}{l}\theta \text { flux across fore boundary of cell } i, j \text {, } \\
k \text {. }\end{array}$ \\
\hline THFL & - & $\theta$ flux across left boundary of cell $\mathrm{i}, \mathrm{j}, \mathrm{k}$. \\
\hline THFR & - & $\begin{array}{l}\theta \text { flux across right boundary of cell } \mathrm{i}, \mathrm{j} \text {, } \\
\mathrm{k} \text {. }\end{array}$ \\
\hline THFT & - & $\theta$ flux across top boundary of cell $\mathrm{i}, \mathrm{j}, \mathrm{k}$. \\
\hline THINB & - & Input. \\
\hline THINL & - & Input. \\
\hline THINR & - & Input. \\
\hline THINT & - & Input. \\
\hline
\end{tabular}


Table A.21: Continuation of the K-FIX(GT) variable list.

\begin{tabular}{|c|c|c|}
\hline Fortran Symbol & $\begin{array}{l}\text { Algebraic } \\
\text { Symbol }\end{array}$ & Definition \\
\hline THN $(\mathrm{I}, \mathrm{J}, \mathrm{K})$ & $\theta^{n}$ & $\begin{array}{l}\text { Void fraction for cell } i, j, k \text { at time level } \\
\text { n. }\end{array}$ \\
\hline $\mathrm{THO}$ & - & Input. \\
\hline $\mathrm{THSF}(\mathrm{I}, \mathrm{J}, \mathrm{K})$ & - & $\begin{array}{l}\text { Integer cell flag to indicate whether } \\
\text { the pressure iteration should be based } \\
\text { on the liquid continuity equation } \\
\text { ( THSF }=1 \text { ), or on the gas continuity } \\
\text { equation ( THSF }=0 \text { ). Each cycle THSF } \\
\text { is set to } 1 \text { if } \theta^{n}<\theta^{*} \text {, or to } 0 \text { if } \theta^{n} \geq \theta^{*} \text {. }\end{array}$ \\
\hline THSTAR & $\theta^{*}$ & $\begin{array}{l}\text { Reference value of void fraction, gener- } \\
\text { ally } \theta^{*}=1 / 2 \text {, set in subroutine SETUP. } \\
\text { THSTAR is used to set the cell flag } \\
\text { THSF }(\mathrm{I}, \mathrm{J}, \mathrm{K}) \text {. }\end{array}$ \\
\hline TIME & - & Input. \\
\hline $\mathrm{TL}(\mathrm{I}, \mathrm{J}, \mathrm{K})$ & $T_{l}$ & Liquid temperature for cell $\mathrm{i}, \mathrm{j}, \mathrm{k}$. \\
\hline TPL & - & Input. \\
\hline TPLD & - & Input. \\
\hline TPR & - & Input. \\
\hline $\mathrm{TS}(\mathrm{I}, \mathrm{J}, \mathrm{K})$ & $T_{s}$ & $\begin{array}{l}\text { NO LONGER IN USE. Calculated } \\
\text { when needed. Saturation temperature } \\
\text { at the pressure } \mathrm{P}(\mathrm{I}, \mathrm{J}, \mathrm{K}) \text {. }\end{array}$ \\
\hline TSTOP & - & Input. \\
\hline $\mathrm{UG}(\mathrm{I}, \mathrm{J}, \mathrm{K})$ & $\left(u_{g}\right)_{i+1 / 2, j, k}$ & Radial momentum velocity for the gas. \\
\hline UGFA & - & $\begin{array}{l}\text { Radial momentum flux for the gas } \\
\text { across the aft boundary of the momen- } \\
\text { tum control volume centered about the } \\
\text { point } i+1 / 2, j, k \text { minus the viscous } \\
\text { stress term SUGA. }\end{array}$ \\
\hline $\mathrm{UGFB}(\mathrm{I})$ & - & $\begin{array}{l}\text { Radial momentum flux for the gas } \\
\text { across the bottom boundary of the mo- } \\
\text { mentum control volume described above } \\
\text { minus the viscous stress term SUGB. }\end{array}$ \\
\hline
\end{tabular}


Table A.22: Continuation of the K-FIX(GT) variable list.

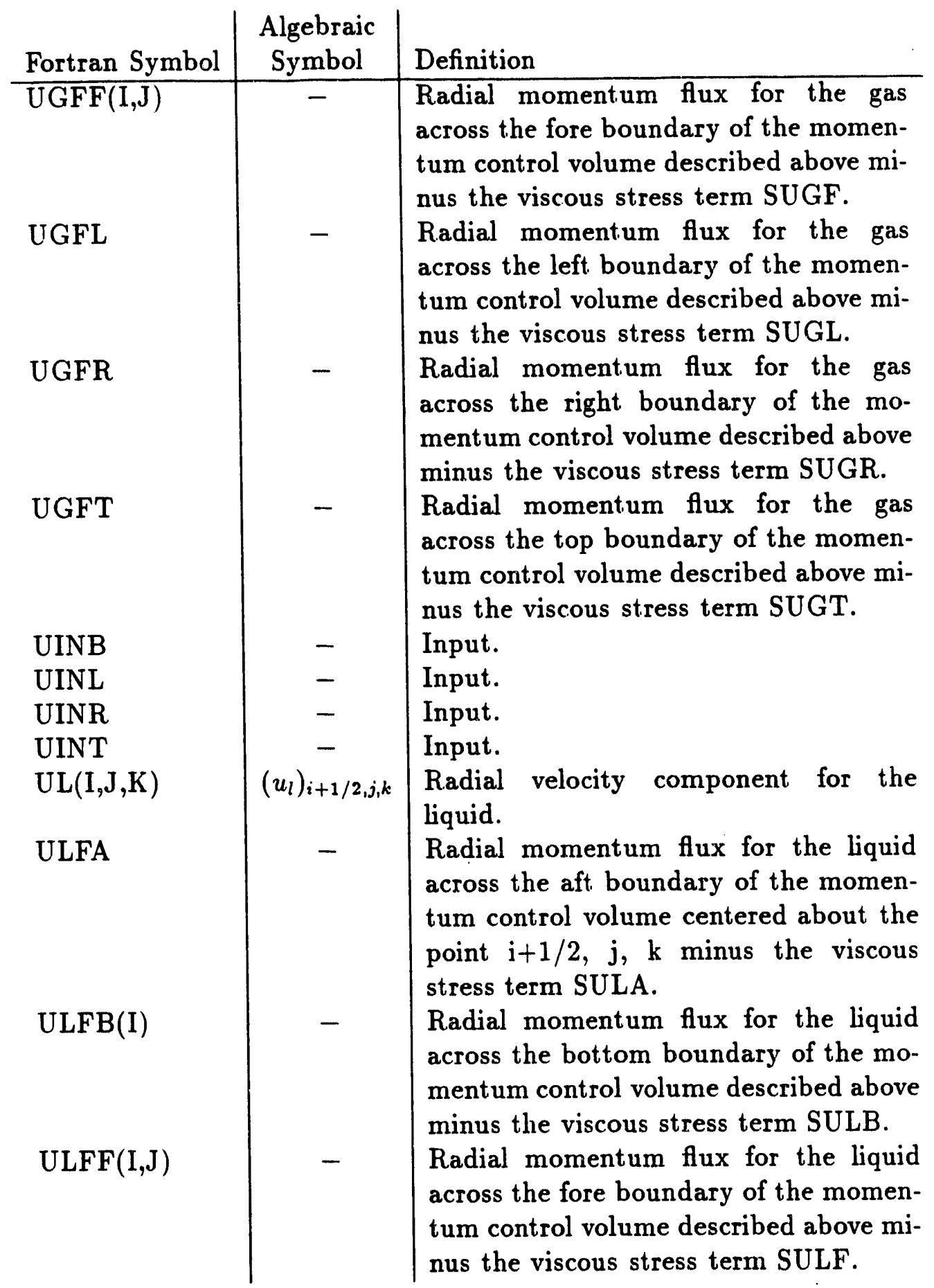


Table A.23: Continuation of the K-FIX(GT) variable list.

\begin{tabular}{|c|c|c|}
\hline Fortran Symbol & $\begin{array}{c}\text { Algebraic } \\
\text { Symbol }\end{array}$ & Definition \\
\hline ULFL & - & $\begin{array}{l}\text { Radial momentum flux for the liquid } \\
\text { across the left boundary of the momen- } \\
\text { tum control volume described above mi- } \\
\text { nus the viscous stress term SULL. }\end{array}$ \\
\hline ULFR & - & $\begin{array}{l}\text { Radial momentum flux for the liquid } \\
\text { across the right boundary of the mo- } \\
\text { mentum control volume described above } \\
\text { minus the viscous stress term SULR. }\end{array}$ \\
\hline ULFT & - & $\begin{array}{l}\text { Radial momentum flux for the liquid } \\
\text { across the top boundary of the momen- } \\
\text { tum control volume described above mi- } \\
\text { nus the viscous stress term SULT. } \\
\text { Input. }\end{array}$ \\
\hline $\mathrm{VG}(\mathrm{I}, \mathrm{J}, \mathrm{K})$ & $\left(v_{g}\right)_{i, j+1 / 2, k}$ & Axial velocity component for the gas. \\
\hline VGFA & - & $\begin{array}{l}\text { Axial momentum flux for the gas across } \\
\text { the aft boundary of the momentum con- } \\
\text { trol volume centered about the point } i \text {, } \\
j+1 / 2, k \text { minus the viscous stress term } \\
\text { SVGA. }\end{array}$ \\
\hline VGFB(I) & - & $\begin{array}{l}\text { Axial momentum flux for the gas across } \\
\text { the bottom boundary of the momentum } \\
\text { control volume described above minus } \\
\text { the viscous stress term SVGB. }\end{array}$ \\
\hline $\operatorname{VGFF}(\mathrm{I}, \mathrm{J})$ & - & $\begin{array}{l}\text { Axial momentum flux for the gas across } \\
\text { the fore boundary of the momentum } \\
\text { control volume described above minus } \\
\text { the viscous stress term SVGF. }\end{array}$ \\
\hline VGFL & - & $\begin{array}{l}\text { Axial momentum flux for the gas across } \\
\text { the left boundary of the momentum } \\
\text { control volume described above minus } \\
\text { the viscous stress term SVGL. }\end{array}$ \\
\hline
\end{tabular}


Table A.24: Continuation of the K-FIX(GT) variable list.

\begin{tabular}{|c|c|c|}
\hline Fortran Symbol & $\begin{array}{c}\text { Algebraic } \\
\text { Symbol }\end{array}$ & Definition \\
\hline VGFR & - & $\begin{array}{l}\text { Axial momentum flux for the gas across } \\
\text { the right boundary of the momentum } \\
\text { control volume described above minus } \\
\text { the viscous stress term SVGR. }\end{array}$ \\
\hline VGFT & - & $\begin{array}{l}\text { Axial momentum flux for the gas across } \\
\text { the top boundary of the momentum } \\
\text { control volume described above minus } \\
\text { the viscous stress term SVGT. }\end{array}$ \\
\hline VINB & - & Input. \\
\hline VINL & - & Input. \\
\hline VINR & - & Input. \\
\hline VINT & - & Input. \\
\hline $\mathrm{VL}(\mathrm{I}, \mathrm{J}, \mathrm{K})$ & $\left(v_{l}\right)_{i, j+1 / 2, k}$ & Axial velocity component for the liquid. \\
\hline VLFA & - & $\begin{array}{l}\text { Axial momentum flux for the liquid } \\
\text { across the aft boundary of the momen- } \\
\text { tum control volume centered about the } \\
\text { point } i, j+1 / 2, k \text { minus the viscous } \\
\text { stress term SVLA. }\end{array}$ \\
\hline $\operatorname{VLFB}(\mathrm{I})$ & - & $\begin{array}{l}\text { Axial momentum flux for the liquid } \\
\text { across the bottom boundary of the mo- } \\
\text { mentum control volume described above } \\
\text { minus the viscous stress term SVLB. }\end{array}$ \\
\hline $\operatorname{VLFF}(\mathrm{I}, \mathrm{J})$ & - & $\begin{array}{l}\text { Axial momentum flux for the liquid } \\
\text { across the fore boundary of the momen- } \\
\text { tum control volume described above mi- } \\
\text { nus the viscous stress term SVLF. }\end{array}$ \\
\hline VLFL & - & $\begin{array}{l}\text { Axial momentum flux for the liquid } \\
\text { across the left boundary of the momen- } \\
\text { tum control volume described above mi- } \\
\text { nus the viscous stress term SVLL. }\end{array}$ \\
\hline
\end{tabular}


Table A.25: Continuation of the K-FIX(GT) variable list.

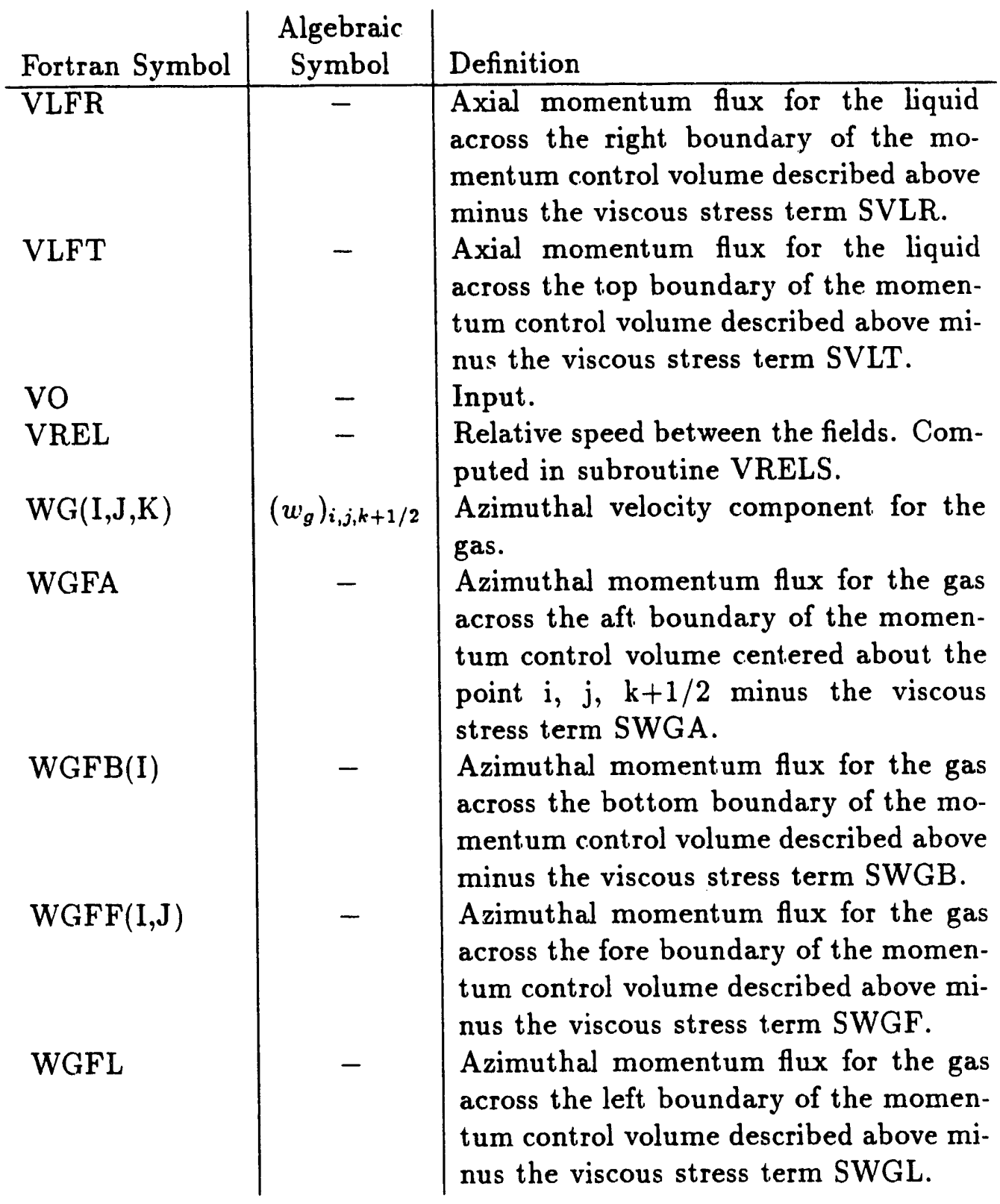


Table A.26: Continuation of the K-FIX(GT) variable list.

\begin{tabular}{|c|c|c|}
\hline Fortran Symbol & $\begin{array}{l}\text { Algebraic } \\
\text { Symbol }\end{array}$ & Definition \\
\hline WGFR & - & $\begin{array}{l}\text { Azimuthal momentum flux for the gas } \\
\text { across the right boundary of the mo- } \\
\text { mentum control volume deicubed above } \\
\text { minus the viscous stress term SWGR. }\end{array}$ \\
\hline WGFT & - & $\begin{array}{l}\text { Azimuthal momentum flux for the gas } \\
\text { across the top boundary of the momen- } \\
\text { :um control volume described above mi- } \\
\text { nus the viscous stress term SWGT. }\end{array}$ \\
\hline WINB & - & Input. \\
\hline WINL & - & Input. \\
\hline WINR & - & Input. \\
\hline WINT & - & Input. \\
\hline $\mathrm{WL}(\mathrm{I}, \mathrm{J}, \mathrm{K})$ & $\left(w_{l}\right)_{i, j, k+1 / 2}$ & $\begin{array}{l}\text { Azimuthal velocity component for the } \\
\text { liquid. }\end{array}$ \\
\hline WLFA & - & $\begin{array}{l}\text { Azimuthal momentum flux for the liq- } \\
\text { uid across the aft boundary of the mo- } \\
\text { mentum control volume centered about } \\
\text { the point } i, j, k+1 / 2 \text { minus the viscous } \\
\text { stress term SWLA. }\end{array}$ \\
\hline WLFB(I) & - & $\begin{array}{l}\text { Azimuthal momentum flux for the liq- } \\
\text { uid across the bottom boundary of the } \\
\text { momentum control volume described } \\
\text { above minus the viscous stress term } \\
\text { SWLB. }\end{array}$ \\
\hline WLFF(I,J) & - & $\begin{array}{l}\text { Azimuthal momentum flux for the liq- } \\
\text { uid across the fore boundary of the mo- } \\
\text { mentum control volume described above } \\
\text { minus the viscous stress term SWLF. }\end{array}$ \\
\hline WLFL & - & $\begin{array}{l}\text { Azimuthal momentum flux for the liq- } \\
\text { uid across the left boundary of the mo- } \\
\text { mentum control volume described above } \\
\text { minus the viscous stress term SWLL. }\end{array}$ \\
\hline
\end{tabular}


Table A.27: Continuation of the K-FIX(GT) variable list.

\begin{tabular}{|c|c|c|}
\hline Fortran Symbol & $\begin{array}{l}\text { Algebraic } \\
\text { Symbol }\end{array}$ & Definition \\
\hline WLFR & - & $\begin{array}{l}\text { Azimuthal momentum flux for the liq- } \\
\text { uid across the right boundary of the mo- } \\
\text { mentum control volume described above } \\
\text { minus the viscous stress term SWLR. } \\
\text { Azimuthal momentum flux for the liq- } \\
\text { uid across the top boundary of the mo- } \\
\text { mentum control volume described above } \\
\text { minus the viscous stress term SWLT. }\end{array}$ \\
\hline WO & - & Input. \\
\hline XAIR(I,J,K) & $\left(x_{a i r}\right)^{n+1}$ & $\begin{array}{l}\text { Mass fraction of air in the gas at the } \\
\text { new time step }(n+1) \text {. }\end{array}$ \\
\hline XAIRINB & - & Input. \\
\hline XAIRINL & - & Input. \\
\hline XAIRINR & - & Input. \\
\hline XAIRINT & - & Input. \\
\hline XAIRN $(I, J, K)$ & $\left(x_{a i r}\right)^{n}$ & $\begin{array}{l}\text { Mass fraction of air in the gas at the old } \\
\text { time step }(n) .\end{array}$ \\
\hline XAIRO & - & Input. \\
\hline $\mathrm{XDEB}(\mathrm{I}, \mathrm{J}, \mathrm{K})$ & $\left(x_{\text {deb }}\right)^{n+1}$ & $\begin{array}{l}\text { Mass fraction of debris in the liquid at } \\
\text { the new time step }(n+1) \text {. }\end{array}$ \\
\hline XDEBINB & - & Input. \\
\hline XDEBINL & - & Input. \\
\hline XDEBINR & - & Input. \\
\hline XDEBINT & - & Input. \\
\hline $\mathrm{XDEBN}(\mathrm{I}, \mathrm{J}, \mathrm{K})$ & $\left(x_{d e b}\right)^{n}$ & $\begin{array}{l}\text { Mass fraction of debris in the liquid at } \\
\text { the old time step }(n) \text {. }\end{array}$ \\
\hline XDEBO & - & Input. \\
\hline XNNEW(I,J,K) & $(N)^{n+1}$ & $\begin{array}{l}\text { Dispersion number density at the new } \\
\text { time step }(n+1) \text {. }\end{array}$ \\
\hline $\mathrm{XNOLD}(\mathrm{I}, \mathrm{J}, \mathrm{K})$ & $(N)^{n}$ & $\begin{array}{l}\text { Dispersion number density at the old } \\
\text { time step }(n) \text {. }\end{array}$ \\
\hline $\mathrm{XYZMK}(\mathrm{M}, \mathrm{N})$ & - & $\begin{array}{l}\text { Location of the } M^{\text {th }} \text { marker. } \mathrm{N}=1 \\
\text { holds the } \mathrm{x} \text { coordinate, } \mathrm{N}=2 \text { holds the } \\
\mathrm{y} \text { coordinate, and } \mathrm{N}=3 \text { holds the } \mathrm{z} \\
\text { coordinate. }\end{array}$ \\
\hline
\end{tabular}



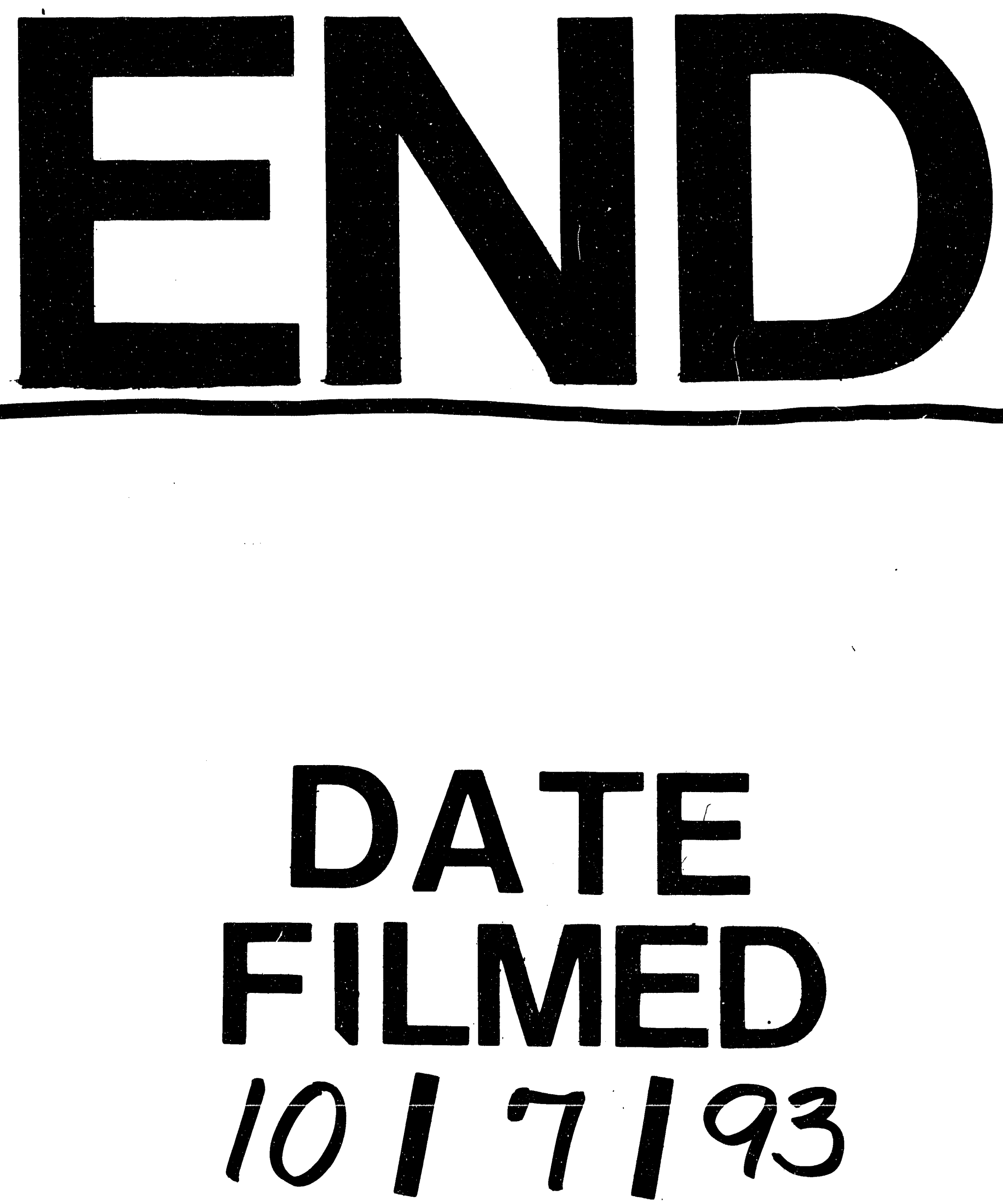
